Aus der Abteilung Nephrologie und Rheumatologie

(Prof. Dr. med. G. A. Müller)

im Zentrum Innere Medizin

der Medizinischen Fakultät der Universität Göttingen

\title{
Einfluss der ACE-Hemmer-Therapie auf das Fortschreiten der Niereninsuffizienz bei Patienten mit Alport-Syndrom
}

Datenerhebung an deutschen kindernephrologischen Zentren

\author{
Inaugural-Dissertation \\ zur Erlangung des Doktorgrades \\ der Medizinischen Fakultät \\ der Georg-August-Universität zu Göttingen
}

vorgelegt von

Christopher Michael Bach

aus Calgary/ Kanada

Göttingen 2011 
Dekan:

1.Berichterstatter:

2.Berichterstatter/in:

Tag der mündlichen Prüfung: $\quad$ 20.03.2012 


\section{Inhaltsverzeichnis}

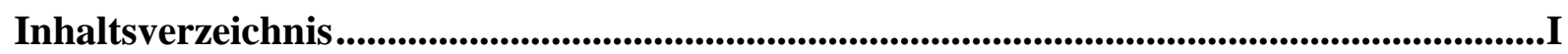

Abkürzungsverzeichnis........................................................................................................ II

Abbildungsverzeichnis ......................................................................................................... III

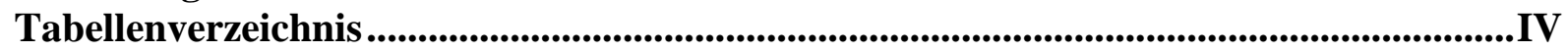

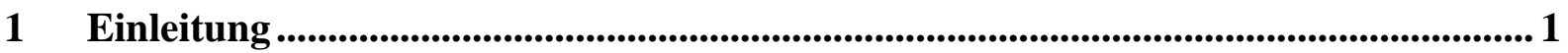

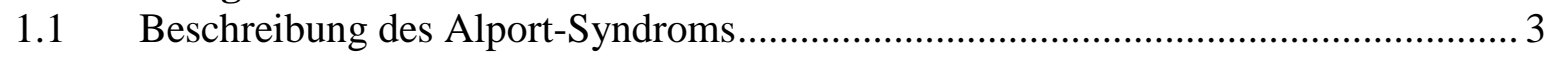

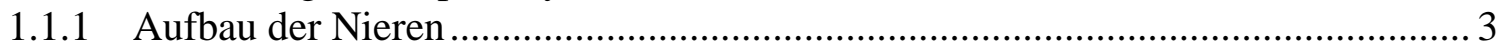

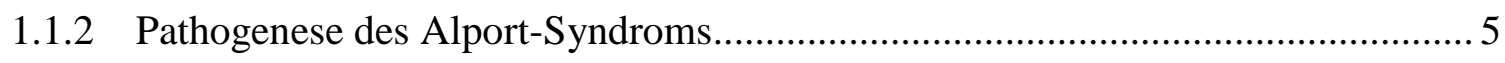

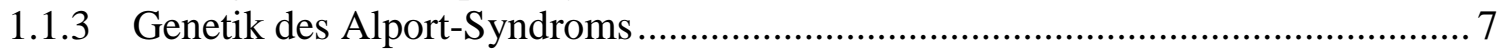

1.1.4 Klinische Manifestation und Verlauf des Alport-Syndroms ................................

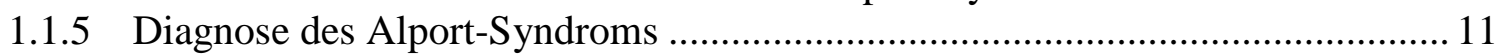

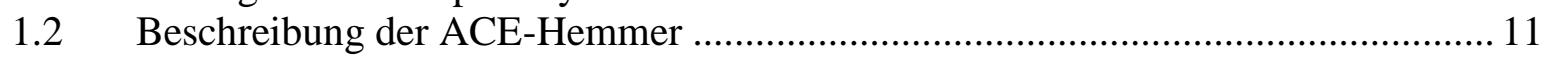

1.2.1 Wirkmechanismus der ACE-Hemmer bei Nephropathien .................................. 13

1.2.2 Wirkmechanismus der ACE-Hemmer beim Alport-Syndrom ............................ 15

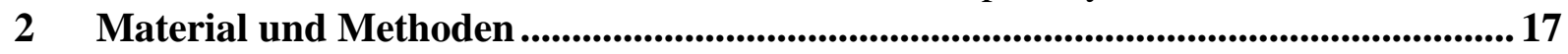

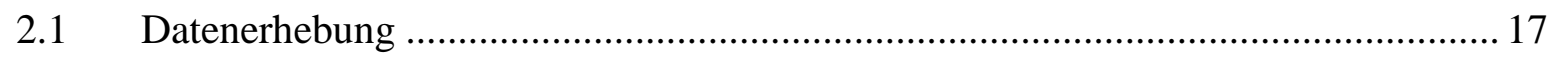

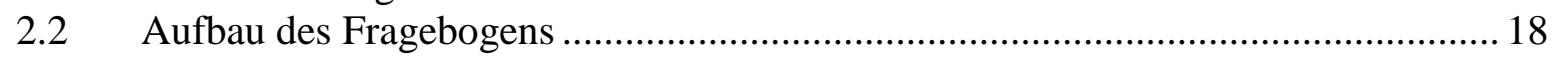

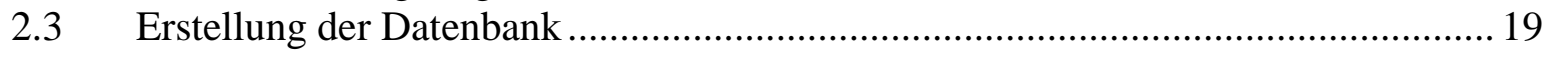

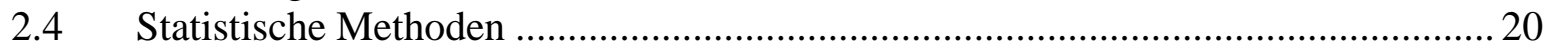

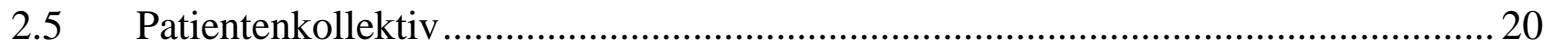

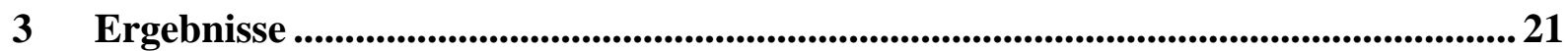

3.1 Auswertung des Patientenkollektivs ................................................................ 21

3.1.1 Verteilung der Patienten auf verschiedene Zentren ......................................... 21

3.1.2 Alters- und Geschlechtsverteilung der Patienten .............................................. 22

3.1.3 Verteilung der Erbgänge der aufgenommenen Patienten................................... 22

3.1.4 Diagnostische Sicherung des Alport-Syndroms ............................................. 23

3.1.5 Behandlung mit ACE-Hemmern im Patientenkollektiv ...................................... 24

3.2 Vergleich des aktuellen Registers mit den historischen Daten .............................. 25

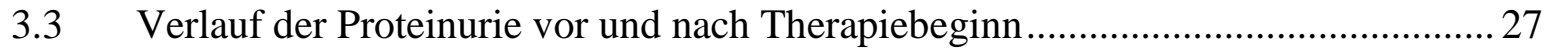

3.4 Darstellung eines möglichen Nutzens des Zeitpunktes der Therapie ..................... 29

3.5 Auswirkung des Alters während der Therapie ....................................................... 32

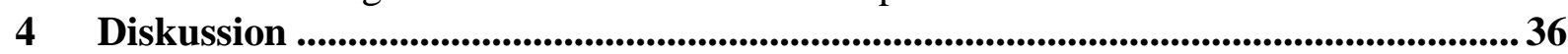

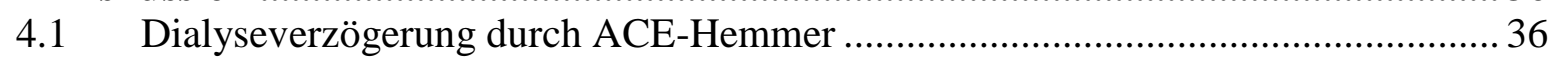

4.2 Senkung der Proteinurie durch ACE-Hemmer..................................................... 39

4.3 Nutzen eines frühen gegenüber späten Therapiebeginns mit ACE-Hemmern ........ 42

4.4 Bedeutung des Alters während der Therapie mit ACE-Hemmern......................... 45

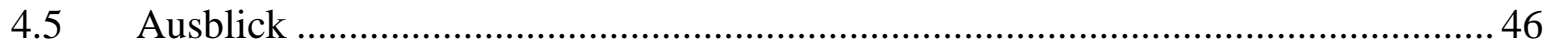

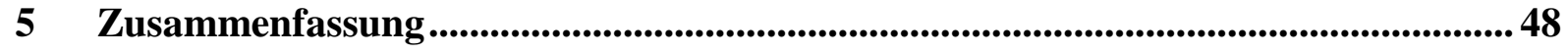

6 Anhang: Fragebogen.......................................................................................................................5 50

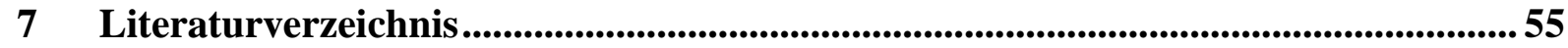




\section{Abkürzungsverzeichnis}

$\begin{array}{ll}\text { ACE } & \text { Angiotensin-Konversions-Enzym } \\ \text { AS } & \text { Alport-Syndrom } \\ \text { CTGF } & \text { Connective Tissue Growth Factor } \\ \text { DNA } & \text { Desoxyribonukleinsäure } \\ \text { et al. } & \text { und andere } \\ \text { g } & \text { Gramm } \\ \text { GBM } & \text { Glomeruläre Basalmembran } \\ \text { GFR } & \text { Glomeruläre Filtrationsrate } \\ \text { MMP-2 } & \text { Matrix-Metalloproteinase-2 } \\ \text { MMP-9 } & \text { Matrix-Metalloproteinase-9 } \\ \text { p } & \text { Signifikanzwert } \\ \text { TGF- } 3 & \text { Transforming Growth Factor- } 3 \\ \alpha & \text { Alpha } \\ > & \text { größer, über } \\ < & \text { kleiner }\end{array}$




\section{Abbildungsverzeichnis}

Abbildung 1: Verteilung der Patienten auf die Zentren .21

Abbildung 2: Verteilung der Vererbung der Patienten .23

Abbildung 3: Art der Untersuchung zur Sicherung der Diagnose des Alport-Syndroms ........ 24

Abbildung 4: Zeitpunkt der Einnahme der ACE-Hemmer .25

Abbildung 5: Vergleich des Altersdurchschnitts der aktuellen mit der historischen Gruppe.. 27

Abbildung 6: Verlauf der Proteinurie vor und nach Beginn der Therapie .29

Abbildung 7: Verlauf der Proteinurie vor und nach Beginn der Therapie bei früher und später Einnahme. 32

Abbildung 8: Verlauf der Proteinurie vor und nach Beginn der Therapie bei den unter und über 20-jährigen Patienten 35 


\section{Tabellenverzeichnis}

Tabelle 1: Klinische Merkmale der verschiedenen Alport-Syndrom-Phasen ........................ 10

Tabelle 2: Überblick über das Alter und Geschlecht der registrierten Patienten .................... 22

Tabelle 3: Aufteilung der Geschlechter in den Erbgängen ................................................ 23

Tabelle 4: Darstellung der Therapiedauer der 25 Patienten ................................................. 25

Tabelle 5: Verlauf der Proteinurie vor und nach Beginn der Therapie mit ACE-Hemmern ... 28

Tabelle 6: Verlauf der Proteinurie vor und nach Beginn der Therapie bei früher Einnahme .. 30

Tabelle 7: Verlauf der Proteinurie vor und nach Beginn der Therapie bei später Einnahme .. 31

Tabelle 8: Verlauf der Proteinurie vor und nach Beginn der Therapie der unter 20-Jährigen. 33

Tabelle 9: Verlauf der Proteinurie vor und nach Beginn der Therapie der über 20-Jährigen.. 34 


\section{Einleitung}

Das Alport-Syndrom (AS) stellt eine vererbte und voranschreitende Nierenerkrankung dar. Durch eine Mutation in den Genen für das Kollagen IV entwickelt sich ein veränderter Aufbau im kollagenen Bindegewebe der Niere (Netzer et al. 1997). Die eigentliche Filtrationsbarriere für Eiweiße geht verloren. Es kommt durch eine chronische Entzündung und eine daraus resultierende Fibrose der Niere zu einem Verlust der Nierenfunktion. Durch die Vernarbung der Niere entsteht eine Niereninsuffizienz, die für die Patienten eine Dialyse oder Nierentransplantation bedeutet. Patienten, die an dem AS erkranken, werden vorwiegend in den ersten zehn Lebensjahren diagnostiziert. Durch dieses frühe Erkennen der Erkrankung könnte man schon früh mit einer geeigneten Therapie beginnen. Jedoch ist das AS bis heute nicht heilbar. In den letzten Jahren hat sich aufgrund verschiedener Forschungsarbeiten in Tiermodellen die Behandlung mit Angiotensin-Konversions-Enzym (ACE)-Hemmern aber als wirkungsvollste Therapie erwiesen, um zumindest die Progression der Erkrankung und damit die Dialyse zu verzögern.

Das grundlegende Thema dieser Doktorarbeit ist im Rahmen eines europäischen Datenregisters Daten von AS-Patienten aus Deutschland zu sammeln und den Verlauf der Erkrankung anhand von Nierenfunktionsparametern $\mathrm{zu}$ beobachten, zu bewerten und $\mathrm{zu}$ dokumentieren. Die Auswirkungen einer ACE-Hemmer-Therapie werden betrachtet. Des Weiteren soll die Frage beantwortet werden, ob es durch die Therapie zu einem verzögerten Eintritt der Niereninsuffizienz kommt. Das in der Arbeit erstellte Register soll Teil eines europäischen Datenregisters darstellen, das Daten von AS-Patienten europaweit zusammenfasst. Mit Hilfe der ermittelten Daten soll der Nutzen der ACE-Hemmer für ASPatienten belegt werden. Das Register dieser Dissertation soll zusätzlich den Effekt der ACEHemmer zur Verzögerung der Dialyse des AS bekräftigen und als Grundlage für weiterführende Untersuchungen dienen. Durch diese Bestätigung könnte erstmalig eine Therapieempfehlung ausgegeben werden, da es bis jetzt keine offizielle Zulassung für die Einnahme von ACE-Hemmern bei AS-Patienten gibt.

Die Dissertation gibt zunächst einen Überblick über das AS und die ACE-Hemmer. Anschließend werden das Material und die Methoden für die Entstehung des Datenregisters und die Untersuchungen beschrieben. Die Ergebnisse werden in den aktuellen 
Forschungsstand eingefügt, mit diesem verglichen und diskutiert. Abschließend werden die in der Doktorarbeit gewonnenen Ergebnisse zusammengefasst. 


\subsection{Beschreibung des Alport-Syndroms}

Das AS ist eine hereditäre und fortschreitende Nierenerkrankung, die in 60 bis 80 Prozent der Fälle von einer Innenohrschwerhörigkeit und in 25 bis 40 Prozent von spezifischen Augenveränderungen begleitet wird (Kashtan 1999). Die Prävalenz, an dem AS zu erkranken, liegt bei 1: 50.000 Lebendgeburten (Levy und Feingold 2000). Cecil A. Alport beschrieb als erster im Jahre 1927 die Assoziation von familiärer Nephritis und Hörstörungen (Alport 1927). Beim AS kommt es durch eine chronische Entzündung zu einem voranschreitenden Verlust der Nierenfunktion und einer daraus resultierende Fibrose der Niere. Durch die Vernarbung der Niere entsteht eine chronische Niereninsuffizienz. Ungefähr ein Prozent der Dialysepatienten in Deutschland sind AS-Patienten und stellen nach der Zystennierenerkrankung die zweithäufigste Ursache für eine erbliche Niereninsuffizienz dar (Gross 2005).

In der Niere sind vor allem der Aufbau und damit die Funktion der Glomeruli eingeschränkt. Deshalb gehört das AS in das Krankheitsbild der Glomerulopathien. Das AS tritt als eine angeborene Erkrankung auf, die entweder X-chromosomal, autosomal-dominant oder autosomal-rezessiv vererbt wird. Als Leitsymptome gelten eine Hämaturie und Proteinurie, die meistens schon im Kindesalter auftreten. Bei der Hämaturie erscheint Blut im Urin. Von einer Proteinurie spricht man, wenn es zu einem übermäßigen Ausscheiden von Eiweiß über den Urin kommt.

Abhängig von dem Stadium der terminalen Niereninsuffizienz wird beim AS zwischen dem juvenilen und adulten Typ unterschieden. Beim juvenilen Typ kommt es bereits vor dem 30 . Lebensjahr zur terminalen Niereninsuffizienz. Vom adulten Typ spricht man, wenn die Niereninsuffizienz erst nach dem 30. Lebensjahr erreicht wird (Gubler et al. 1981).

\subsubsection{Aufbau der Nieren}

Da es sich beim AS um eine Erkrankung der Niere handelt, wird in diesem Kapitel kurz die Anatomie und Physiologie der Niere dargestellt. Vor allem wird das Nephron erklärt, das die Glomeruli beinhaltet, da diese Einheit der Niere bei den AS-Patienten besonders betroffen ist. Die Nieren liegen links und rechts dicht unter dem Diaphragma und sind von einer Nierenkapsel umgeben. Um die Kapsel liegt zusätzlich eine Fett- und Bindegewebeschicht. Sie ist an der hinteren Bauchwand befestigt und schützt diese. Am mittleren Nierenrand 
befindet sich der Nierenhilus. Hier treten die Nierenarterien, Nierenvenen, Nierenlymphgefäße und der Ureter ein oder aus. Außerdem nimmt am Nierenhilus auch das Nierenbecken seine Position ein, das den Urin vom Nierengewebe sammelt und über den Ureter an die Harnblase abführt.

Das Nierenbecken wird von dem Nierenmark und der Nierenrinde umgeben. Von der Rinde ziehen Ausläufer, die Columnae renales, zum Nierenbecken. Sie unterteilen das Nierenmark in verschiedene Lappen, die Markpyramiden.

Zur Bildung des Urins wird das Blut über ein Gefäßsystem zum Nephron transportiert. Jede Niere erhält ihr Blut über die Nierenarterien aus der Aorta. Diese verzweigen sich in der Niere zu den Zwischenlappenarterien, die in den Markpyramiden in Richtung der Nierenrinde verlaufen und sich zu den Zwischenläppchenarterien verbinden. Aus diesen entspringen die Vasa afferentia, kleinste Arteriolen, die das Blut in Richtung des Nephrons transportieren.

Die Vasa afferentia bilden eine verzweigte, anastomosierende Kapillarschlinge, den Glomerulus, in dem der Primärharn entsteht. Die Vasa efferentia nehmen das Blut aus dem Glomerulus auf, transportieren es zum Tubulussystem und bilden ein weiteres Kapillargebiet. Im Tubulussystem wird der Primärharn durch Resorption und Sekretion verändert und als Sekundärharn ausgeschieden (Schaeffler und Menche 1999). Das mit resorbierten, nicht ausgeschiedenen Stoffen enthaltene Blut wird über die Nierenvene zur Vena cava inferior geleitet.

Die Nieren erfüllen mehrere Aufgaben. Zum einen sind sie wichtige Ausscheidungsorgane. Sie scheiden die Endprodukte des Stoffwechsels und im Körper vorhandene Giftstoffe durch Harnbildung aus. Zum anderen spielen die Nieren eine wichtige Rolle in der Regulierung des Blutdrucks. Dies geschieht über die Kontrolle des Wasser- und Elektrolythaushaltes. Ebenso kontrollieren die Nieren den Säuren-Basenhaushalt und synthetisieren das Hormon Erythropoetin, das zur Herstellung der Erythrozyten benötigt wird.

Erfüllt werden diese Aufgaben durch das Nephron, die funktionelle Untereinheit der Niere. Jedes Nephron besteht aus einem Nierenkörperchen und einem Tubulusapparat. Das Nierenkörperchen setzt sich aus der Bowman-Kapsel und dem Glomerulus zusammen. Beide bilden die Blut-Harn-Schranke. Die Bowman-Kapsel wird in ein viszerales und parietales Blatt gegliedert und umgreift den Glomerulus. Das äußere Blatt dient zur äußeren Begrenzung des Nierenkörperchens. Das innere Blatt besteht aus Podozyten und liegt dem Glomerulus direkt auf. 
Der Glomerulus setzt sich aus mehreren Kapillarschlingen mit Endothelzellen zusammen. Zwischen den Endothezellen und den Podozyten liegt die glomeruläre Basalmembran (GBM), die aus der Fusion der Basallamina der Podozyten und der Endothelzellen entsteht. Die GBM bildet ein Netzwerk, das sich vor allem aus dem Typ-IV-Kollagen, dem Glykoprotein Laminin, dem Glykoprotein Nidogen und aus Heperansulfat-Proteoglykan zusammensetzt (Welsch und Dellert 2005).

Die Adhäsion von Zellen an Typ-IV-Kollagen wird durch Integrinrezeptoren vermittelt (Krishnamurti et al. 1996). Die typische Struktur der GBM ist trilaminär mit einer zentralen Lamina densa und zwei peripheren Laminae rarae (Welsch und Dellert 2005). Diese funktionell und auch medizinisch wichtige Basallamina stellt den wesentlichen Teil des physiologischen glomerulären Filters dar. Der Filter setzt sich aus drei Schichten zusammen. Als erste Barriere dienen die Endothelzellen, deren Poren nur Zellen kleiner als 70 Nanometer durchlassen. Als nächste Filterstruktur ist die GBM zu erwähnen, die den Durchtritt der negativ geladenen Teilchen verhindert.

Als letzte Durchtrittsstelle dient die Bowman-Kapsel mit der Schlitzmembran, die sich zwischen den Ausläufern der Podozyten befindet. Hier wird vor allem der Durchtritt von Proteinen verhindert (Schaeffler und Menche 1999). Durch die Nieren werden Wasser und gelöste Stoffe bis zu einem Molekulargewicht von circa fünf Kilodalton filtriert, während Proteine und Blutzellen im Blut verbleiben (Welsch und Dellert 2005).

AS-Patienten leiden aufgrund des mutierten Gens für Kollagen IV unter einer abnormen Struktur der GBM. Die GBM kann deswegen keine Filtrationsbarriere für Eiweiße darstellen. Proteine und Blutzellen können nicht von den Nieren der AS-Patienten abgefiltert werden. Sie gelangen in den Harn und zerstören die Niere.

\subsubsection{Pathogenese des Alport-Syndroms}

Verantwortlich für den Verlust der Filtrationsbarriere der Niere und die daraus resultierende Glomerulopathie ist eine Mutation des Gens, das für das Kollagen IV kodiert. Dieses Kollagen bildet in der GBM ein Netzwerk, das für Stabilität, Unlöslichkeit und hohe Flexibilität der Niere sorgt (Gross und Weber 2005a). Durch Mutationen in den Genen COL4A3, COL4A4 oder COL4A5 entstehen strukturelle sowie funktionale Defekte in den Typ-IV-Kollagenmolekülen und deshalb in den GBM-Netzwerken. Es kommt zu einer für das 
AS charakteristischen Verdickung und Aufsplitterung der Basalmembran. Die typische trilaminäre Anordnung der GBM mit einer zentral gelegenen Lamina densa und zwei Laminae rarae geht verloren (Gross et al. 2004).

Für den Aufbau der GBM aus Kollagen IV stehen sechs verschiedene $\alpha$-Ketten zur Verfügung (Gross und Weber 2005a). Die einzelnen $\alpha$-Ketten verbinden sich zu den Tripelhelices. Jede Tripelhelix wird aus drei der sechs $\alpha$-Ketten gebildet. Die $\alpha 1$ - und $\alpha 2$-Ketten kommen ubiquitär im Körper vor. Sie sind Bestandteil der GBM in der Niere, der mesangialen Matrix und den vaskulären und tubulären Basalmembranen. Die $\alpha 3-, \alpha 4-, \alpha 5-$ und $\alpha 6-$ Ketten sind dagegen nur Bestandteile der Basalmembran in der Niere, im Auge und Ohr (Hudson et al. 2003). Die einzelnen $\alpha$-Ketten bestehen aus einer kollagenen Domäne (Kollagenschwanz) und einer nicht kollagenen Domäne (NC1-Domäne). Der Kollagenschwanz ist durch eine bestimmte Aminosäurensequenz charakterisiert, die sich aus 1000 Glycin-X-YWiederholungen zusammensetzt. Diese Aminosäurensequenz wird von kurzen, nicht kollagenen Sequenzen unterbrochen, die eine erhöhte Flexibilität der Kette gewährleisten (Hudson et al. 2003). Am Ende des Kollagenschwanzes befindet sich eine weitere nicht kollagene Domäne, die sogenannte 7S-Region. Das aus einer Tripelhelix aufgebaute Kollagenmonomer verknüpft sich mit anderen Monomeren zu einem stabilen Netzwerk. Über dem Carboxyl-Terminus der NC1-Domäne verbinden sich zwei Monomere zu einem Dimer und über dem Amino-Terminus der 7S-Region der vier Kollagendomänen zu einem Tetramer (Hudson et al. 2003).

Um eine weitere Stabilität zu erreichen, gibt es durch Disulfidbrücken zwischen den nichtkollagenen Unterbrechungen des Kollagenschwanzes Seit-Zu-Seit- und End-Zu-EndVerbindungen über die NC1-Domäne.

Mutationen in einen der COL4A3-, COL4A4- oder COL4A5-Gene führen zu einem veränderten Aufbau der GBM. Durch die Mutationen in COL4A kommt es zu einer Abnahme oder sogar einem Ausbleiben der $\alpha 3-, \alpha 4-$ oder $\alpha 5$-Ketten. Beim Aufbau des GBMNetzwerkes werden die $\alpha 3$-, $\alpha 4$ - und $\alpha 5$-Ketten durch die $\alpha 1$ - und $\alpha 2$-Ketten ersetzt. Durch diesen Umbau wird die eigentliche Struktur der GBM zerstört. Die trilaminäre Struktur aus der zentralen Lamina densa und zwei peripheren Laminae rarae geht verloren. Die Lamina densa zeigt Aufsplitterungen und Lamellierungen, wobei eine netzartige bis korbgeflechtete Strukturveränderung der insgesamt verdickten GBM imponiert (Flinter et al. 1988). In 
Untersuchungen wird angenommen, dass die glomeruläre Kapillarwand als Folge der geschädigten GBM ein erhöhtes Potential zur Ruptur bei physiologischem intrakapillären Druck zeigt. Dies ist ein theoretischer Gedanke, der noch nie in vivo oder im Labor beobachtet werden konnte (Kashtan 2005).

Die Änderung der Zusammensetzung und Struktur der GBM verändert auch den Ablauf der Zelladhäsion und Signaltransduktion (Meehan et al. 2009). Die GBM beim AS zeigt eine Überexpression von Zytokinen, die zu einer übermäßigen Produktion von fibrotischem Gewebe führt (Koepke et al. 2007). Diese Änderungen in den glomerulären Zellen werden von einer Veränderung der extrazellulären Matrix begleitet. Zusätzlich tritt eine Überexpression von Fibrose produzierenden Zytokinen auf. Die profibrotischen Zytokine sind TGF- $\beta$, CTGF, Laminin, Fibronectin, Integrine und Metalloproteinasen, die neben profibrotischen Effekten eine proinflammatorische Wirkung besitzen (Abrahamson et al. 2003). Die Mutationen in COL4 bedingen außerdem eine vermehrte Proliferation von Mesangialzellen, die zu einer vermehrten Akkumulation von extrazellulärer Matrix führt (Nishimura et al. 1999). Der genaue Ablauf von der defekten GBM zur tubulointerstitiellen Fibrose und dem Funktionsverlust einzelner Nephrone, der letztlich in der Niereninsuffizienz endet, ist bis heute noch ungeklärt (Gross et al. 2004).

\subsubsection{Genetik des Alport-Syndroms}

Beim AS geht es um eine genetisch vererbte Erkrankung, die aus einer Mutation in den Genen entsteht, die für die $\alpha 3-, \alpha 4-$ oder $\alpha 5$-Kette des Kollagens IV kodieren (Kashtan 1999). Diese Mutation führt zu einem Defekt im Aufbau des Kollagens IV mit den beschriebenen Auswirkungen. Fast ein Prozent der Bevölkerung sind heterozygote Träger für Mutationen in den Alportgenen (Gross und Weber 2005a). Beim AS handelt es sich um Mutationen der Gene COL4A3 auf dem Chromosom 2, COL4A4 ebenfalls auf dem Chromosom 2 und COL4A5 auf dem Chromosom X (Kashtan 2007). Diese sind Isoformen des Kollagen-IVGens. Genauere Forschungen des Kollagen-IV-Gens haben sechs genetische Isoformen detektiert. Eine Mutation in einem der drei von den sechs Isoformen ist bei der Entstehung der AS- Erkrankung beteiligt (Kashtan 2004). Jedes Gen kodiert für eine der $\alpha$-Ketten, die zum Aufbau des Kollagens IV benötigt werden. 
Da eine Mutation von jedem dieser Gene zum AS führen kann, liegt beim AS ein heterogener Übertragungsweg zugrunde (M`Rad et al.1992). Das AS weist eine genotypisch und phänotypisch variable Erkrankung auf. Phänotypisch zeigt sich ein heterogenes Erscheinungsbild. Die Patienten unterscheiden sich also im Auftreten der AS-typischen Symptome. Nicht bei allen tritt neben der Beteiligung der Niere auch eine Innenohrschwerhörigkeit und Augenveränderung auf.

Die Übertragung des AS kann zwischen den Generationen auf drei verschiedene Arten erfolgen: X-chromosomal, autosomal-rezessiv oder autosomal-dominant.

Über 80 Prozent der AS-Patienten erkranken an der X-chromosomalen Form. Die Prävalenz liegt bei 1:5.000 (Gross et al. 2003b). Eine Mutation im COL4A5-Gen auf dem langen Arm des Chromosoms X ist die Ursache der X-chromosomalen Form (Barker et al.1990). Dieses Gen kodiert für die $\alpha 5$-Kette des Typ-IV-Kollagens und sorgt für eine Abnormalität dieser Kette.

Der Großteil der über diesen Vererbungsweg Betroffenen besteht aus männlichen Erkrankten, die fast alle eine terminale Niereninsuffizienz entwickeln. 75 Prozent der Männer bei der Xchromosomalen Form des AS erkranken an der juvenilen Form. Bei 25 Prozent tritt die terminale Niereninsuffizienz erst nach dem 30. Lebensjahr (adulte Form) auf (Gross et al. 2003b).

Frauen mit einem X-chromosomalen Vererbungsweg zeigen als heterozygote Träger meist einen milderen Krankheitsverlauf. Bei 85 Prozent der Frauen, die durch den Xchromosomalen Erbgang erkranken, funktionieren die Nieren ein Leben lang vollständig. Bei diesen Frauen tritt nur eine leichte Mikrohämaturie auf. Sie sind in der Lage, ihr mutiertes XChromosom durch das nicht mutierte X-Chromosom zu kompensieren (Kashtan 2004). Eine terminale Niereninsuffizienz betrifft nur wenige Frauen und wird meistens erst nach dem 60 . Lebensjahr erreicht (Butkowski et al. 1990). Die Frauen fungieren als sogenannte Konduktoren. Das bedeutet, dass Frauen mit einer 50-prozentigen Wahrscheinlichkeit das AS an ihre Kinder übertragen können (Kashtan 2007). Eine Vater-Sohn-Transmission ist dagegen nicht möglich. Bis jetzt sind über 300 Mutationen im COL4A5-Gen bekannt (Kashtan 2004). Die autosomale Vererbung (circa 15 bis 20 Prozent des AS) wird in einen autosomalrezessiven und autosomal-dominanten Vererbungsweg unterteilt. Hier liegt die Prävalenz bei 1:50.000 (Gross et al. 2003b). Die Vererbung kann von beiden Elternteilen auf Sohn oder Tochter übertragen werden. Im Gegensatz zur X-chromosomalen Vererbung können 
erkrankte Väter beim autosomalen Erbgang AS auch an ihre Söhne vererben (Gross et al. 2004). Mutationen in beiden Allelen des COL4A3 (kodiert für die $\alpha 3$-Kette) oder des COL4A4 (kodiert für die $\alpha 4-$ Kette) verursachen die autosomal-rezessive Form des AS.

Bei Patienten mit einem autosomal-rezessiven Erbgang lässt sich klinisch ein gleich schwerer Krankheitsverlauf bei Männern und Frauen feststellen. Das klinische Erscheinungsbild und der Verlauf sind beim autosomal-rezessiven Weg dem X-chromosomalen ähnlich (Kashtan 1999). Bei 80 Prozent der autosomal-rezessiven Form kommt es wie beim X-chromosomalen Erbgang zu einer juvenilen Form des AS.

AS-Patienten mit molekulargenetisch nur einem betroffenem Allel (COL4A3 oder COL 4A4) bilden die autosomal-dominante Form des AS. Dieser Vererbungsweg macht zirka fünf Prozent der AS-Patienten aus. Sie erben die Erkrankung von einem Elternteil, das ebenfalls Symptome zeigt. Es können sowohl Frauen als auch Männer erkranken. Häufig sorgen heterozygote Mutationen in COL4A3 oder COL4A4 für ein geringes Krankheitsbild, wie eine Mikrohämaturie ohne Proteinurie und ohne deutliche Abnahme der Nierenfunktion (Kashtan 2005).

Bei 10-15 Prozent der AS-Patienten kann die Familienanamnese bezüglich von Nierenerkrankungen leer sein. Mögliche Ursachen können Neumutationen und Keimbahnmutationen der Mutter sein (Atkin et al. 1988).

\subsubsection{Klinische Manifestation und Verlauf des Alport-Syndroms}

Unabhängig von der Art der Vererbung präsentiert sich das AS immer als Glomerulosklerose, deren Verlauf in vier Phasen unterteilt wird. Wie lange ein Patient in einer Phase jeweils verweilt, hängt vor allem von der Art der Mutation ab. Bei AS-Patienten kann eine Mutation entweder zu einem Verlust von Aminosäuren einer $\alpha$-Kette oder zu strukturellen Veränderungen der Aminosäurenreihenfolge führen. Patienten, bei denen die Mutation zu einem verkürzten Protein (Frameshift-, Nonsense- oder Large-Rearrangement-Mutationen) führt, erleiden ein Nierenversagen mit zirka 20 Jahren. Verändert sich die Proteinstruktur (Frame- oder Missense-Mutationen), erreichen die Patienten erst später das Stadium des Nierenversagens (Gross et al. 2004). Die häufigste Mutation bei AS ist die Glycinsubstitution, die zu einem Abknicken der Tripelhelix-Struktur führt. Die Schwere der Mutation hängt von der Lokalisation der Mutation ab (Gross et al. 2003b). 
Die erste Phase des AS-Verlaufes wird durch eine Hämaturie und eine milde Proliferation der mesangialen Zellen charakterisiert. Im Mikroskop zeigt sich eine dünne GBM, die an manchen Stellen Lamellierungen mit normalen Podozytenfußfortsätzen aufweist. Dieses Stadium repräsentiert die frühe Kindheit der AS-Patienten, in der sowohl die Proteinurie als auch der Blutdruck normal sind (Kashtan 1999).

Patienten in der zweiten Phase zeigen zusätzlich eine Proteinurie bei noch intakter glomerulärer Filtrationsrate. Histologisch lässt sich eine vermehrte Proliferation von mesangialen Zellen und eine Verdickung der GBM erkennen. Es kommt zu einer Verschmelzung der Podzytenfußfortsätze. Im Glomerulus kann eine fokale glomeruläre Sklerose auftreten. Das Tubulointerstitium bleibt dagegen von einer Fibrose unberührt.

In der dritten Phase nimmt die glomeruläre Filtrationsrate ab. Eine fokale glomeruläre Sklerose ist sicher vorhanden. Auch das Tubulointerstitium ist fibrotisch betroffen.

Patienten, die die vierte Phase erreicht haben, zeigen das Vollbild einer Niereninsuffizienz mit einer Globalsklerose im Glomerulus und einem fibrotischen Interstitium (Kashtan 2005). Diese Patienten müssen sich einer Dialysetherapie unterziehen.

Die meisten Patienten mit X-chromosomaler oder autosomal-rezessiver Vererbung sind in der vierten Phase zwischen 16 und 35 Jahre alt und gehören in die Gruppe des juvenilen Typs (Kashtan 1999). Bei den autosomal-dominanten Patienten tritt dagegen die Niereninsuffizienz erst zwischen 45 und 60 Jahren ein. Diese gehören der Gruppe des adulten AS-Typs an.

\begin{tabular}{|c|c|c|c|c|}
\hline Phase & I & II & III & IV \\
\hline $\begin{array}{l}\text { Klinische } \\
\text { Merkmale }\end{array}$ & $\begin{array}{l}\text { - Hämaturie } \\
\text {-keine } \\
\text { Proteinurie } \\
\text { - normale GFR }\end{array}$ & $\begin{array}{l}\text { - Hämaturie } \\
\text { - Proteinurie } \\
\text { - normale GFR }\end{array}$ & $\begin{array}{l}\text { - Hämaturie } \\
\text { - Proteinurie } \\
\text {-Abnahme der } \\
\text { GFR }\end{array}$ & $\begin{array}{l}\text { - Hämaturie } \\
\text { - Proteinurie } \\
\text {-terminale } \\
\text { Niereninsuffizienz }\end{array}$ \\
\hline $\begin{array}{l}\text { Veränderungen } \\
\text { im Interstitium }\end{array}$ & keine & geringe & Fibrose & Fibrose \\
\hline
\end{tabular}

Tabelle 1: Klinische Merkmale der verschiedenen Alport-Syndrom-Phasen 


\subsubsection{Diagnose des Alport-Syndroms}

Hämaturie, Proteinurie, positive Familienanamnese, Innenohrschwerhörigkeit, Sehschwäche und Strukturveränderungen der GBM sind die gültigen Diagnosekriterien für das AS (Gross und Weber 2005a). Da es sich beim AS um eine Erbkrankheit handelt, ist die Familienanamnese von großer Bedeutung für die Diagnose. Ein bekannter Nierenschaden oder Taubheit bei nahen Verwandten lassen ein AS vermuten.

Bestätigt wird die Erkrankung entweder durch eine humangenetische Detektierung des mutierten Gens oder eine Nierenbiopsie zur Untersuchung der Zellstruktur. Eine positive Nierenbiopsie und eine positive molekulargenetische Untersuchung auch bei nahen Verwandten beweisen das AS (Kashtan 1999).

\subsection{Beschreibung der ACE-Hemmer}

Einer der neuesten Therapieansätze beim AS ist die Therapie durch ACE-Hemmer. Bei den ACE-Hemmern handelt es sich um Medikamente, die durch eine kompetitive Hemmung des Angiotensin-Konversions-Enzym (ACE) wirken (Fischler und Follath 1999). Das ACE katalysiert Angiotensin I zu Angiotensin II. Dieses Enzym ist wichtiger Bestandteil des Renin-Angiotensin-Aldosteron-Systems, das eine wesentliche Rolle beim Wasser- und Elektrolythaushalt und bei der Regulierung des Blutdrucks spielt. Das System findet seinen Ursprung in der Bildung von Angiotensinogen in der Leber und der Freisetzung von Renin aus der Niere.

Renin sorgt für die Umwandlung von Angiotensinogen zu Angiotensin I. Das ACE katalysiert anschließend Angiotensin I zu Angiotensin II. Nach der Herstellung von Angiotensin II interagiert es an den Blutgefäßen mit Angiotensinrezeptoren (AT1-Rezeptoren), wobei die Blutgefäße kontrahieren. Zusätzlich wird durch Angiotensin II das Aldosteron aus der Zona glomerulosa in der Nebennierenrinde freigesetzt. Dieses Aldosteron bewirkt an der Niere eine vermehrte Retention von Natriumionen. Das resorbierte Natrium zieht Wasser aus dem Nierentubulus in das Blutsystem des Körpers zurück. Durch die Kontraktion der Blutgefäße und Retention von Natrium und Wasser steigt der Blutdruck an.

Die ACE-Hemmer wirken durch kompetitive Bindung an das ACE und hemmen die Umwandlung von Angiotensin I zu Angiotensin II (Fischler und Follath 1999). Nimmt die 
Angiotensin-II-Bildung ab, wird weniger Aldosteron aus der Nebennierenrinde freigesetzt (Mutschler et al. 2001). Der periphere Gefäßwiderstand sinkt und Natrium sowie Wasser werden vermehrt über die Niere ausgeschieden. Dadurch sinkt der Blutdruck.

Die folgende Auflistung zeigt die in Deutschland benutzen ACE- Hemmer (Ruß 2008):

- Benazepril

- Captopril

- Cilazapril

- Enalapril

- Fosinopril

- Imidapril

- Lisinopril

- Moexipril

- Perindopril

- Quinapril

- Ramipril

- Spirapril

- Trandolapril.

Mit Ausnahme von Captopril und Lisinopril dreht es sich bei den ACE-Hemmern um Prodrugs, aus denen durch Esterhydrolyse die eigentlichen Wirksubstanzen entstehen (Mutschler et al. 2001). Die Wirkhalbwertszeit beträgt je nach Medikament zwischen zwei bis 20 Stunden.

ACE-Hemmer werden vorwiegend bei erhöhtem Blutdruck, Herzinsuffizienz und einer Proteinurie bei diabetischer Nephropathie eingesetzt (Fischler und Follath 1999).

Die meisten ACE-Hemmer werden renal ausgeschieden. Deshalb muss bei einer Niereninsuffizienz wegen der verlangsamten Ausscheidung mit einer verstärkten Wirkung durch Akkumulation gerechnet werden. Ramipril, Fosinopril, Benazepril, Spirapril und Trandolapril werden primär hepatisch abgebaut und biliär ausgeschieden. Die Dosierung 
dieser Medikamente muss daher bei einer Niereninsuffizienz nur gering modifiziert werden (Fischler und Follath 1999).

Bei zehn Prozent der Patienten entsteht als unerwünschte Nebenwirkung vor allem Reizhusten, der mit einem verlangsamten Abbau und Anreicherung von Bradykinin durch ACE-Hemmer in Verbindung gebracht wird (von Dicipinigaitis 2006). Zusätzlich kann eine orthostatische Hypotension hervorgerufen werden, vor allem bei gleichzeitiger Therapie mit Diuretika (Fischler und Follath 1999). Durch die verminderte Aldosteronsekretion oder durch die Kombination von ACE-Hemmern mit kaliumsparenden Diuretika kann eine Hyperkaliämie entstehen (Mutschler et al. 2001). Eine Erhöhung des Serumkreatinins nach Beginn einer ACE-Hemmer-Therapie tritt am häufigsten bei Nierenarterienstenose, Herzinsuffizienz und Hypovolämie auf (Hricik et al. 1983).

In einem Prozent der Fälle beobachtet man ein akutes Nierenversagen, besonders bei Risikopatienten wie zum Beispiel bei Patienten mit einer bilateralen Nierenarterienstenose (Bakris und Weir 2000). Angioneurotische Ödeme in der Lippe, Zunge oder im Rachen sind bei ein bis zwei Prozent der Patienten zu beobachten (Slater et al. 1988).

Manchmal leiden Patienten bei einer ACE-Hemmer-Therapie unter Geschmackstörungen, Kopfschmerzen, Übelkeit, Schwindelgefühl, Diarrhoe, Muskelkrämpfen, Photosensibilisierung oder allergischen Hautreaktionen (Mutschler et al. 2001). Während einer Schwangerschaft und beim Stillen dürfen ACE-Hemmer nicht eingenommen werden. Bei Kindern besteht die Gefahr einer Hypoplasie der Lunge und des Schädels, verbunden mit Wachstumsstörungen, Nierenfunktionsbeeinträchtigungen und sogar fötalen oder neonatalen Todesfällen (Sedman et al. 1995).

\subsubsection{Wirkmechanismus der ACE-Hemmer bei Nephropathien}

Viele bereits durchgeführte Forschungsarbeiten beweisen, dass nicht nur bei den diabetischen, sondern auch bei nicht diabetischen Nephropathien der Einsatz von ACE-Hemmern den progressiven Verlauf chronischer Nierenerkrankungen positiv beeinflusst. Der Funktionsverlust der Niere wird durch die Therapie verlangsamt. Man geht davon aus, dass alle chronischen Nephropathien, unabhängig von der ursprünglichen Ursache, den gleichen pathologischen Mechanismus der renalen Progression zugrunde liegen (Chiurchiu et al. 2005). Alle Nephropathien enden in den gleichen Veränderungen: systemische Hypertonie, 
Anstieg des glomerulären Drucks und der Permeabilität, interstitielle Entzündung sowie Vernarbung.

Besonders in den klinischen Studien über den Einsatz von ACE-Hemmern bei diabetischer Nephropathie fand man eine Korrelation zwischen erhöhter Proteinurie und dem Rückgang der glomerulären Filtrationsrate (Chiurchiu et al. 2005). ACE-Hemmer vermindern die Verschlechterung der glomerulären Filtrationsrate, indem sie die Proteinurie bei diabetischer Nephropathie senken (Lewis et al. 1993). Auch bei nichtdiabetischer Nephropathie wurde dieser Effekt festgestellt (The Gisen Group 1997).

Eine Ursache der Proteinurie ist ein erhöhter systemischer Blutdruck bei Nephropathien, durch den sich ein erhöhter glomerulärer Druck entwickelt und das Auftreten der Proteinurie begünstigt. Durch die Behandlung mit ACE-Hemmern dilatieren die Vasa efferentia an der Niere. Der periphere Blutdruck, damit auch der Druck im Glomerulus, wird gesenkt (Zatz et al. 1986).

Da ACE-Hemmer die Herstellung von Angiotensin II verhindern, entsteht ein weiterer positiver Effekt zur Aufrechterhaltung der Nierenfunktion. Angiotensin II stellt einen entscheidenden Mediator bei den Umstrukturierungen der Niere bei Nephropathien dar.

Angiotensin II wirkt vasokonstriktorisch und erhöht über eine Verengung der Vasa efferentia den glomerulären Druck. Zudem sorgt Angiotensin II als Wachstumsfaktor zur Aktivierung von Fibroblasten, die zu einer Synthese von Matrix bildenden Proteinen führen. Dadurch entsteht eine Differenzierung der Tubulusepithelzellen in Myofibroblasten, die eine Anreicherung von extrazellulärer Matrix begünstigen. Die Nierenzellen hypertrophieren und das Nierengewebe nimmt ab. Zusätzlich induziert Angiotensin II profibrotische Zytokine mit proinflammatorischen Effekten (Wolf 2005).

Diese Effekte von Angiotensin II werden einerseits durch die Freisetzung von TGF- $\beta$ und PAI-1 (Plasminogen activator inhibitor type 1) induziert. Andererseits aktiviert Angiotensinn II als proinflammatorisches Zytokin Monozyten und Makrophagen (Mezzano et al. 2001). Hierdurch trägt das Renin-Angiotensin-System entscheidend zur Entstehung der Fibrose bei progredienten Nierenerkrankungen bei. Die kompetitive Blockade des ACE durch ACEHemmer bewirkt einen antiinflammatorischen und antifibrotischen Effekt. 


\subsubsection{Wirkmechanismus der ACE-Hemmer beim Alport-Syndrom}

Die erfolgreich durchgeführten Studien der Behandlung von Nephropathien mit ACEHemmern und die erfolgreiche Herstellung von COL4A3-Mäusen im Tiermodell, die dem Phänotyp des humanen AS ähneln, haben die Situation für die AS-Therapie verändert. An dem Tiermodell konnte die Therapie mit ACE-Hemmern getestet werden. Zusätzlich belegte im Jahre 2004 die Veröffentlichung der „Effect of Strict blood pressure Control and ACE inhibition on the progression of chronic renal failure in Pediatric patients" (ESCAPE-Study: Wühl et al. 2004), dass Kinder sowohl mit erblichen als auch erworbenen Nierenerkrankungen von der Therapie mit Ramipril profitieren. Bei den meisten Kindern mit arterieller Hypertonie wurde durch eine sechsmonatige Einnahme von Ramipril der Blutdruck gesenkt und das Ausmaß an Proteinurie nahm ab. Das Erreichen des Endstadiums konnte hinausgezögert werden (Wühl et al. 2004).

Da es sich beim AS ebenfalls um eine chronische Nephropathie handelt, geht man davon aus, dass auch beim AS eine Therapie mit ACE-Hemmern von großem Nutzen sein kann.

Die ACE-Hemmer senken auch beim AS den Blutdruck. Jedoch zeigen AS-Patienten während ihrer Erkrankung über einen langen Zeitraum keine erhöhten Blutdruckwerte. Erst im fortgeschrittenen Stadium der Erkrankung entwickelt sich eine Hypertension, die die Entwicklung der Fibrose entscheidend beeinflusst. Deshalb sind eher die blutdruckunabhängigen Effekte von ACE-Hemmern für die AS-Therapie bedeutsam. Zum einen verzögern sich durch die Therapie mit Ramipril im Tiermodell das Auftreten und der Schweregrad von Urämie und Proteinurie. Zum anderen wird die Ablagerung von extrazellulärer Matrix sowie interstieller und glomerulärer Fibrose reduziert. Dieser antifibrotische Effekt ist auf die Downregulation von Transforming Growth Factor- $\beta$ (TGFB), Matrix-Metalloproteinase-2 (MMP-2), Matrix-Metalloproteinase-9 (MMP-9), Connective Tissue Growth Factor (CTGF), Laminin1, Nidogen, Typ-I-Kollagen und Fibronectin unter ACE-Therapie zurückzuführen (Gross und Weber 2005b).

Einen besonders hohen nephroprotektiven Effekt durch die ACE-Hemmer hat im AlportTiermodell die Abnahme der profibrotischen Zytokine TGFß und CTGF. Beide Wachtsumsfaktoren übernehmen bei der Glomerulosklerose und interstitiellen Fibrose eine wichtige Rolle. Obwohl der genaue Mechanismus der Wirkung von ACE-Hemmern beim AS 
noch unbekannt ist, lassen die Versuche an den Tiermodellen vermuten, dass die Unterdrückung der Zytokine und der Kollagenproduktion durch die Podozyten und die antifibrotischen sowie antiinflammatorischen Effekte wichtiger als die antihypertensive Wirkung sind (Gross und Kashtan 2009). 


\section{Material und Methoden}

In diesem Kapitel werden die Datenerhebung für den Einfluss der ACE-Hemmer-Therapie auf Patienten mit dem AS und der erstellte Fragebogen mit der Datenbank beschrieben. Anschließend werden die für die Auswertung verwendeten statistischen Verfahren und die für die Aufnahme ins Datenregister gewählten Kriterien erläutert.

\subsection{Datenerhebung}

Das Ziel dieser Arbeit ist es, Daten von AS-Patienten in Deutschland zu sammeln und diese im Verlauf ihrer Erkrankung zu beobachten und auszuwerten. Da es sich bei dieser Arbeit um einen Teil eines europaweiten Projektes zur Erfassung von Daten von AS-Patienten handelt, wurde zur Gewährleistung einer zukünftigen einheitlichen Datenerhebung ein standardisierter Fragebogen erarbeitet.

Der Fragebogen soll als Grundlage für das europäische Datenregister genutzt werden, um den Krankheitsverlauf der AS-Patienten darzustellen. Mit Hilfe dieses europäischen Registers soll der Nutzen der ACE-Hemmer bei AS ermittelt werden. Dieses Projekt wurde durch die EthikKommission der Georg-August-Universität am 20.11.2007 unter der Auftragsnummer 10/11/06 und dem Studientitel „, European initiative towards delaying renal failure in Alport syndrome" genehmigt.

Der fünfseitige Fragebogen wurde für diese Dissertation in Deutschland an verschiedene kindernephrologische Zentren verteilt. Von diesen haben elf die Erstellung des Datenregisters unterstützt. Es sind die Zentren in München, Leipzig, Leer, Köln, Erlangen, Heidelberg, Frankfurt, Sontheim, Halle, Göttingen und Dortmund.

Die Befragung der Patienten gemäß den zugesandten Fragebögen übernahmen die behandelnden Ärzte der einzelnen Zentren. Als Zielgruppe galten vor allem am AS erkrankte Kinder, die entweder bereits mit ACE-Hemmern behandelt werden oder nicht. 


\subsection{Aufbau des Fragebogens}

Der erstellte Fragebogen (siehe im Anhang: Fragebogen) unterteilt sich in sieben Abschnitte, in denen gezielt wichtige Daten zur Erfassung des Nutzens der ACE-Hemmer bei den ASPatienten erfragt werden.

Im ersten Abschnitt werden die Patienten gebeten, formale Daten wie Name, Geburtsdatum, Geschlecht, Staatsangehörigkeit, Größe und Gewicht anzugeben.

Der zweite Abschnitt befasst sich mit der Familienanamnese. Der Patient macht Angaben zur Art der Vererbung und berichtet über betroffene Verwandte. Hier interessiert vor allem, ob ein Verwandter dialysepflichtig ist und wenn ja, in welchem Alter die Dialyse begonnen hat. Der dritte Abschnitt beschäftigt sich mit der Diagnosefindung des Patienten. Gibt es beim Patienten eine Nierenbiopsie oder eine molekulargenetische Untersuchung zur Sicherung des AS? Die Art der Untersuchung wurde von den einzelnen Zentren selbst entschieden.

Der vierte Abschnitt behandelt den Verlauf der Therapie. Es wird die Auswahl möglicher Medikamente und vor allem das Alter bei Beginn der medikamentösen Therapie hinterfragt. Im fünften Abschnitt werden wertvolle Symptome und Nierenfunktionsparameter des Patienten angesprochen. Der Patient soll Angaben zu einer möglichen Proteinurie in Gramm pro 24 Stunden sowie zu seinen Nierenfunktionsparametern wie Kreatinin in Milligramm pro Deziliter, Kreatinin-Clearance in Milliliter pro Minute, Harnstoff in Milligramm pro Deziliter, Cholesterin in Milligramm pro Deziliter und seinem Blutdruck machen.

Der sechste Abschnitt untersucht, ob ein Patient dialysepflichtig ist oder ob er sich bereits einer Nierentransplantation unterzogen hat. Falls eines der beiden Ereignisse zutrifft, interessiert das Alter, in dem er mit der Dialyse begonnen hat oder ihm eine Niere transplantiert wurde.

Zuletzt berichtet der Patient im Abschnitt sieben über eventuelle Nebenwirkungen durch die medikamentöse Therapie wie Hyperkaliämie, Husten, Hypotonie, akutes Nierenversagen und Rhabdomyolyse.

Die Patienten wurden durch die behandelnden Ärzte der Zentren über die geplante Datenerfassung aufgeklärt. Es wurden in der Dissertation nur Fragebögen mit einer vom Patienten unterschriebenen Einverständniserklärung ausgewertet, aber auch diejenigen, die vom Patienten selbst dem Register zur Verfügung gestellt wurden. 


\subsection{Erstellung der Datenbank}

Die von den Zentren oder direkt von den Patienten zurückgesandten Fragebögen einschließlich der Arztbriefe wurden zentral in einem Safe im Universitätsklinikum Göttingen eingeschlossen. Die Daten der Fragebögen wurden mit der Software Open Office 3.2 Calc erfasst und übersichtlich dokumentiert. Jeder Patient wurde aus Datenschutzgründen mit einer Nummer versehen. Der erste Patient erhielt die Nummer 001, der letzte 051.

Die nächsten Spalten der Datenbank beinhalten das Geburtsdatum des Patienten und das ihn betreuende Zentrum. Danach werden die Patienten in Träger oder Konduktoren unterschieden und nach der Art des Erbganges aufgeteilt. In den weiteren Spalten werden sowohl die Art der Diagnosefeststellung dokumentiert, als auch gezeigt, ob Verwandte des Patienten am AS leiden.

Danach beschäftigt sich die Datenbank mit der möglichen Therapie durch ACE-Hemmer. Hier lag das Hauptaugenmerk auf dem Beginn der Therapie: In welchem Alter erhielten die Patienten die ACE-Hemmer-Therapie und wie war die Nierenfunktion vor Therapiebeginn?

Proteinuriewerte unter 0,2 Gramm pro 24 Stunden vor dem Start mit ACE-Hemmern bedeuten eine frühe ACE-Hemmer-Gabe. Patienten, die bereits einen gemessenen Proteinuriewert über 0,2 Gramm pro 24 Stunden hatten, fielen unter die Kategorie eines späteren Therapiebeginns. Hatten die Nieren bereits 25 Prozent ihrer Funktion bei dem Start mit ACE-Hemmern eingebüßt, begann die Therapie zu einem sehr späten Zeitpunkt der Erkrankung (nephrotoxisches Stadium). Die Proteinuriewerte wurden in den einzelnen Zentren in standardisierten Laboren bestimmt und in Gramm pro 24 Stunden angegeben.

Außerdem werden in dem Register mögliche Nebenwirkungen der ACE-Hemmer wie Hypotonie, Hyperkaliämie, Husten, Synkope, Rhabdomyolyse, Angioödem, akutes Nierenversagen und Schwindel angegeben sowie die Werte für Proteinurie, Serumkreatinin und Kreatininclearance eingetragen. Zusätzlich werden der Blutdruck der einzelnen Patienten jeweils vor und nach dem Start der Therapie sowie die aktuellsten Werte genannt.

Die weiteren Spalten beschäftigen sich mit den Endpunkten der Erkrankung. Ist der Patient schon dialysepflichtig beziehungsweise nierentransplantiert und wenn ja, im welchem Alter startete die Therapie? Den Beginn der Dialyse entschieden die einzelnen Zentren selbst. Hier gab es keine Vorgaben durch die Untersuchung. 
Interessant sind auch dialysepflichtige Verwandte und ihr Alter beim Start der Dialyse. Die letzten beiden Spalten vermerken, ob der Patient auch von Erkrankungen am Ohr beziehungsweise am Auge betroffen ist.

\subsection{Statistische Methoden}

Die in Open Office 3.2 Calc erfassten Daten wurden mithilfe des Computerprogramms Statistica 8.0.725.0 statistisch analysiert. Die Ergebnisse der Daten wurden im SAS 9.2 berechnet. Es wurde eine statistische Signifikanz bei einer Irrtumswahrscheinlichkeit von kleiner als fünf Prozent angenommen $(\mathrm{p}<0.05)$. Die Berechnung erfolgte durch eine zwei faktorielle Varianzanalyse mit Messwiederholung. Die Hauptfaktoren der Berechnungen waren der Zeitpunkt des Starts der Therapie und der Verlauf der Proteinurie während der Therapie.

Die berechneten Ergebnisse wurden durch einen Boxplot, ein 95-Prozent-Konfidenzintervall oder einen Range Plot Graphen graphisch dargestellt.

Eine ausführliche statistische Beratung erfolgte durch einen professionellen Biometriker/Statistiker der Abteilung Medizinische Statistik der Universität Göttingen.

\subsection{Patientenkollektiv}

Insgesamt 51 der verteilten Fragebögen wurden zurückgesendet. Um jedoch in die Datenbank aufgenommen zu werden, mussten von den Patienten folgende Kriterien erfüllt werden:

- Bestätigung des AS durch Biopsie oder molekulargenetische Untersuchung auch bei nahen Verwandten

- Angabe der Proteinuriewerte in Gramm pro 24 Stunden vor und nach dem Start der Therapie mit dem ACE-Hemmer

- ein Mindestalter von 3 Jahren.

25 der 51 Patienten erfüllten die Auswertungskriterien und wurden ins Register aufgenommen. Die übrigen 26 Patienten wurden in einer gesonderten Datenbank gespeichert und sollen nach Vervollständigung ihrer Daten bei künftigen Auswertungen berücksichtigt werden. 


\section{Ergebnisse}

In diesem Kapitel werden die Ergebnisse der Auswertung der Fragebögen aufgezeigt. Zuerst wird die Auswertung des Patientenkollektivs dargestellt. Anschließend werden die Wirkung der ACE-Hemmer auf die Verzögerung der Dialyse und eine historische Gruppe ohne eine Therapie vorgestellt. Des Weiteren werden die Ergebnisse des Verlaufes der Proteinurie unter Therapie und der Zeitpunkt des Therapiebeginns erläutert.

\subsection{Auswertung des Patientenkollektivs}

\subsubsection{Verteilung der Patienten auf verschiedene Zentren}

Die nachstehende Tabelle zeigt die Verteilung der 25 registrierten Patienten auf die verschiedenen Zentren:

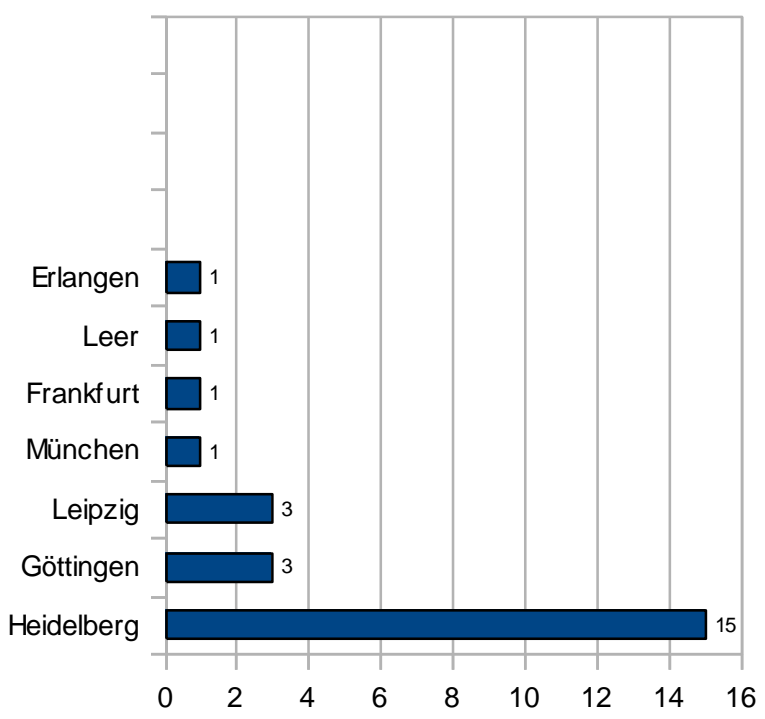

Abbildung 1: Verteilung der Patienten auf die Zentren

Vier Zentren schickten nicht ausreichende Daten zurück. Diese konnten für die Dissertation nicht berücksichtigt werden. 


\subsubsection{Alters- und Geschlechtsverteilung der Patienten}

Der jüngste Patient war bei der Auswertung der Daten drei Jahre alt, der älteste 39. Das Durchschnittsalter der registrierten Patienten betrug 19,16 Jahre. Fünf der Patienten waren jünger als zehn Jahre, von denen eine weibliche und vier männliche in die Datenbank aufgenommen wurden. Acht Patienten waren zwischen 11 und 20 (zwei Frauen und sechs Männer), neun zwischen 21 und 30 Jahre (fünf Frauen und vier Männer) und drei (eine Frau und zwei Männer) älter als 30.

\begin{tabular}{|l|l|l|l|l|}
\hline & < 10 Jahre & 11-20 Jahre & $21-30$ Jahre & > 30 Jahre \\
\hline Anzahl der Patienten & 5 & 8 & 9 & 3 \\
\hline Weiblich & 1 & 2 & 5 & 1 \\
\hline Männlich & 4 & 6 & 4 & 2 \\
\hline
\end{tabular}

Tabelle 2: Überblick über das Alter und Geschlecht der registrierten Patienten

\subsubsection{Verteilung der Erbgänge der aufgenommenen Patienten}

Das AS wurde bei 14 von den 25 aufgenommenen Patienten durch den X-chromosomalen und bei elf durch den autosomal-rezessiven Erbgang vererbt. Eine autosomal-dominante Vererbung konnte keiner der Patienten aufweisen. Eigentlich ist bei der Verteilung der Vererbung beim AS bekannt, dass über 80 Prozent der AS-Patienten durch die Xchromosomale Vererbung erkranken. Dass bei diesem Register auch vermehrt eine autosomale Vererbung vorliegt, kann vorwiegend durch die Aufnahme einiger Patienten mit türkischer Abstammung verursacht sein. Bei diesen Patienten liegt häufig ein autosomalrezessiver Erbgang aufgrund einer Blutsverwandtschaft der Eltern vor. 


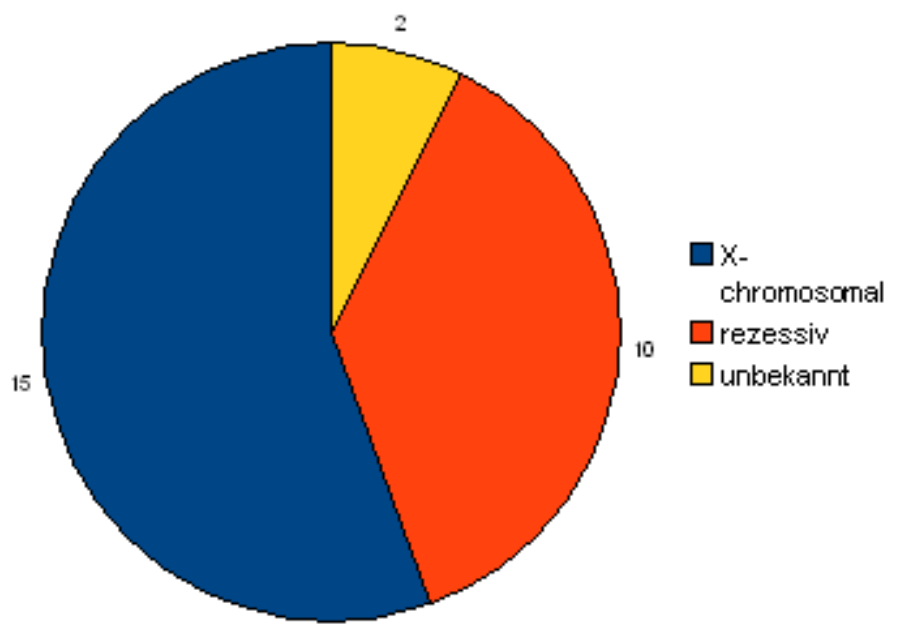

Abbildung 2: Verteilung der Vererbung der Patienten

Beim X-chromosomalen Erbgang konnten zwei Frauen und dreizehn Männer erfasst werden. Sieben Frauen und drei Männer zeigten eine autosomal-rezessive Vererbung. Von diesen 25 Patienten sind 23 Träger des AS. Zwei weibliche Patienten fungieren als Konduktoren.

\begin{tabular}{|l|l|l|}
\hline Geschlecht & X-chromosomal & Autosomal-rezessiv \\
\hline Weiblich & 2 & 7 \\
\hline Männlich & 13 & 3 \\
\hline
\end{tabular}

Tabelle 3: Aufteilung der Geschlechter in den Erbgängen

\subsubsection{Diagnostische Sicherung des Alport-Syndroms}

Bei zwölf Patienten wurde die Niere biopsiert, während bei weiteren sieben eine molekulargenetische Untersuchung stattfand. Bei sechs Patienten gab es eine Sicherung des AS durch nahe Verwandte wie Geschwister und Eltern. 


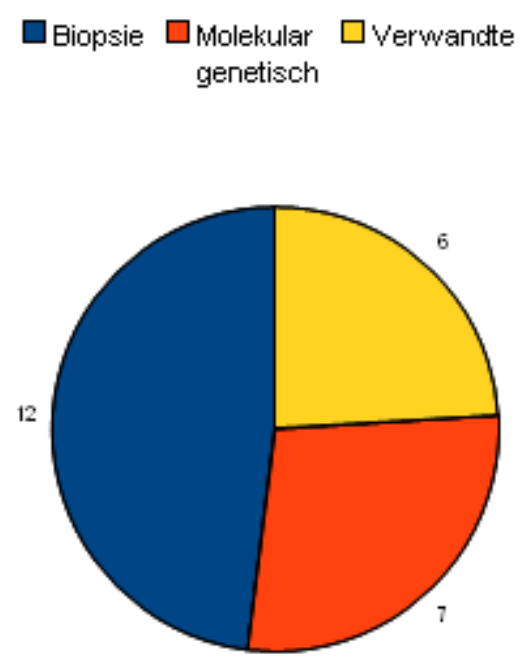

Abbildung 3: Art der Untersuchung zur Sicherung der Diagnose des Alport-Syndroms

\subsubsection{Behandlung mit ACE-Hemmern im Patientenkollektiv}

Alle 25 Patienten der Datenbank gaben eine Behandlung mit ACE-Hemmern an. Dreizehn Patienten waren während der Therapie jünger, zwölf älter als 20 Jahre.

Sechs Patienten wurden in einem frühen Stadium der Erkrankung behandelt. Bei 19 Patienten begann die Therapie erst in einem späten Stadium. Bei keinem Patienten der Datenbank wurde der ACE-Hemmer im nephrotoxischen Stadium gegeben. Der jüngste Patient war bei Therapiebeginn ein Jahr alt, der älteste 33 Jahre. 


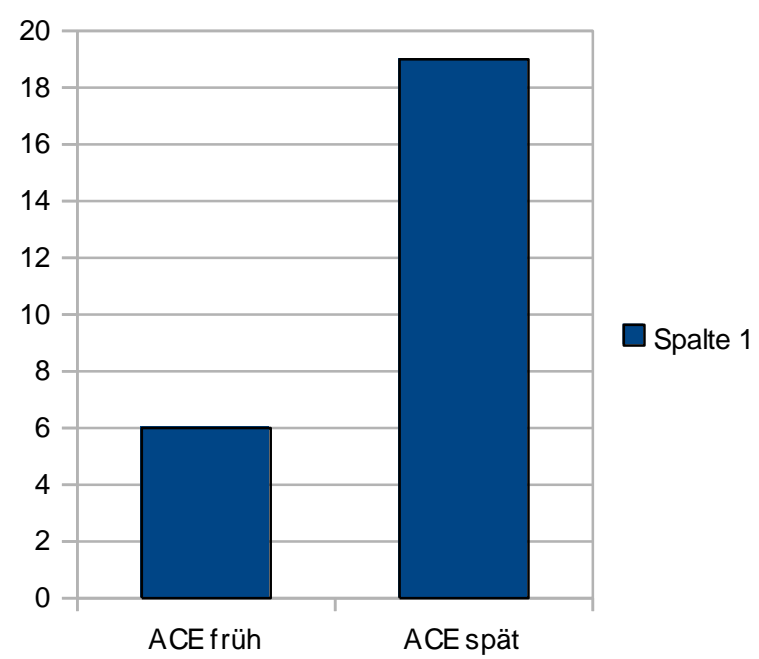

Abbildung 4: Zeitpunkt der Einnahme der ACE-Hemmer

Die kürzeste Therapiedauer lag bei zwei Patienten bei einem Jahr, die längste bei 15 Jahren. Bei zwei Patienten war die Dauer unbekannt.

\begin{tabular}{|l|l|l|l|l|l|l|l|l|l|l|l|}
\hline $\begin{array}{l}\text { Therapiedauer in } \\
\text { Jahre }\end{array}$ & 1 & 2 & 3 & 4 & 5 & 6 & 7 & 8 & 9 & 10 & 15 \\
\hline Anzahl der Patienten & 2 & 5 & 4 & 3 & 4 & 1 & 1 & 2 & 1 & 1 & 1 \\
\hline
\end{tabular}

Tabelle 4: Darstellung der Therapiedauer der 25 Patienten

Keiner der aufgenommenen Patienten zeigte irgendwelche Nebenwirkungen durch die Therapie mit den ACE-Hemmern.

\subsection{Vergleich des aktuellen Registers mit den historischen Daten}

Das Ziel der ACE-Hemmer-Therapie beim AS ist es, den Eintritt der Dialyse um Jahre zu verzögern. In den letzten Jahren begann das Stadium der terminalen Niereninsuffizienz bei AS-Patienten durchschnittlich im 20. Lebensjahr (Gross und Weber 2005b). In diesem Test wurde die Wirkung der ACE-Hemmer bei AS-Patienten aufgezeigt. Da alle 25 untersuchten Patienten bereits eine Therapie mit ACE-Hemmer begonnen hatten und damit keine aktuelle 
Kontrollgruppe zur Verfügung stand, wurde zur genauen Veranschaulichung der Wirkung der ACE-Hemmer als Kontrollgruppe Daten von Patienten aus früheren Jahren zum Vergleich verwendet.

Als Endpunkt dieser Untersuchung gilt die terminale Niereninsuffizienz, also das Stadium der Erkrankung, in dem die AS-Patienten von einer Dialyse oder einer Nierentransplantation abhängig sind. Mit Hilfe des Boxplots wurde die Verteilung des Alters graphisch aufgezeigt und verglichen. Keiner der 25 Patienten aus dem aktuellen Register hat das Stadium der Niereninsuffizienz erreicht. Somit ist ein direkter Vergleich dieser beiden Gruppen noch nicht möglich, da im Moment noch zwei verschiedene Endpunkte vorliegen.

Um eine Tendenz der Wirkung des AS aufzuzeigen, wurde eine graphische Darstellung in Bezug auf den Altersdurchschnitt gewählt. Zuerst wurden beide Boxplots einzeln ausgewertet und beschrieben, um anschließend einen Ausblick über die Entwicklung des Eintrittes der Dialyse bei den therapierten Patienten zu geben und zu diskutieren.

Bei dem historischen Register handelt es sich um 168 AS-Patienten, die alle das Stadium der Dialyse erreicht haben, der Jüngste mit neun und der Älteste mit 41 Jahren. 50 Prozent dieser Patienten sind zwischen 17 und 27 Jahren alt, mit einem Median von 23 Jahren. 25 Prozent sind beim Erreichen der Dialyse unter 17 und 25 Prozent über 27 Jahre. Alle Patienten hatten keine ACE-Hemmer-Therapie erhalten.

Aus dem aktuellen Register haben alle eine Therapie mit ACE-Hemmern begonnen und keiner hat das Stadium der Niereninsuffizienz erreicht. Deshalb wurde bei diesen Patienten die Altersverteilung untersucht. Der jüngste Patient war bei der Erfassung der Daten drei Jahre, der älteste 39 Jahre alt. 50 Prozent dieser Patienten, die das Stadium der Niereninsuffizienz unter Therapie der ACE-Hemmer noch nicht erreicht haben, sind zwischen 14 und 25 mit einem Median von 19 Jahren alt. 25 Prozent der Patienten sind unter 14 und 25 Prozent über 25 Jahre.

Eine vergleichende Betrachtung der beiden Boxplots zeigt, dass beide bezogen auf den Altersdurchschnitt schon jetzt auf einer Höhe liegen. Vergleicht man beide Boxplots nach Eintritt der Niereninsuffizienz aller Patienten aus dem aktuellen Register mit den historischen Daten mit dem Endpunkt Niereninsuffizienz, liegt der Altersdurchschnitt bei Eintritt in die Dialyse aller Patienten des aktuellen Registers deutlich höher als bei der historischen Kontrollgruppe. Der Altersdurchschnitt bei den Patienten mit Therapie durch ACE-Hemmer 
wird bei Eintritt der Dialyse in den nächsten Jahren noch ansteigen, da keiner dieser Patienten des aktuellen Registers bis jetzt das Stadium der terminalen Niereninsuffizienz erreicht hat.

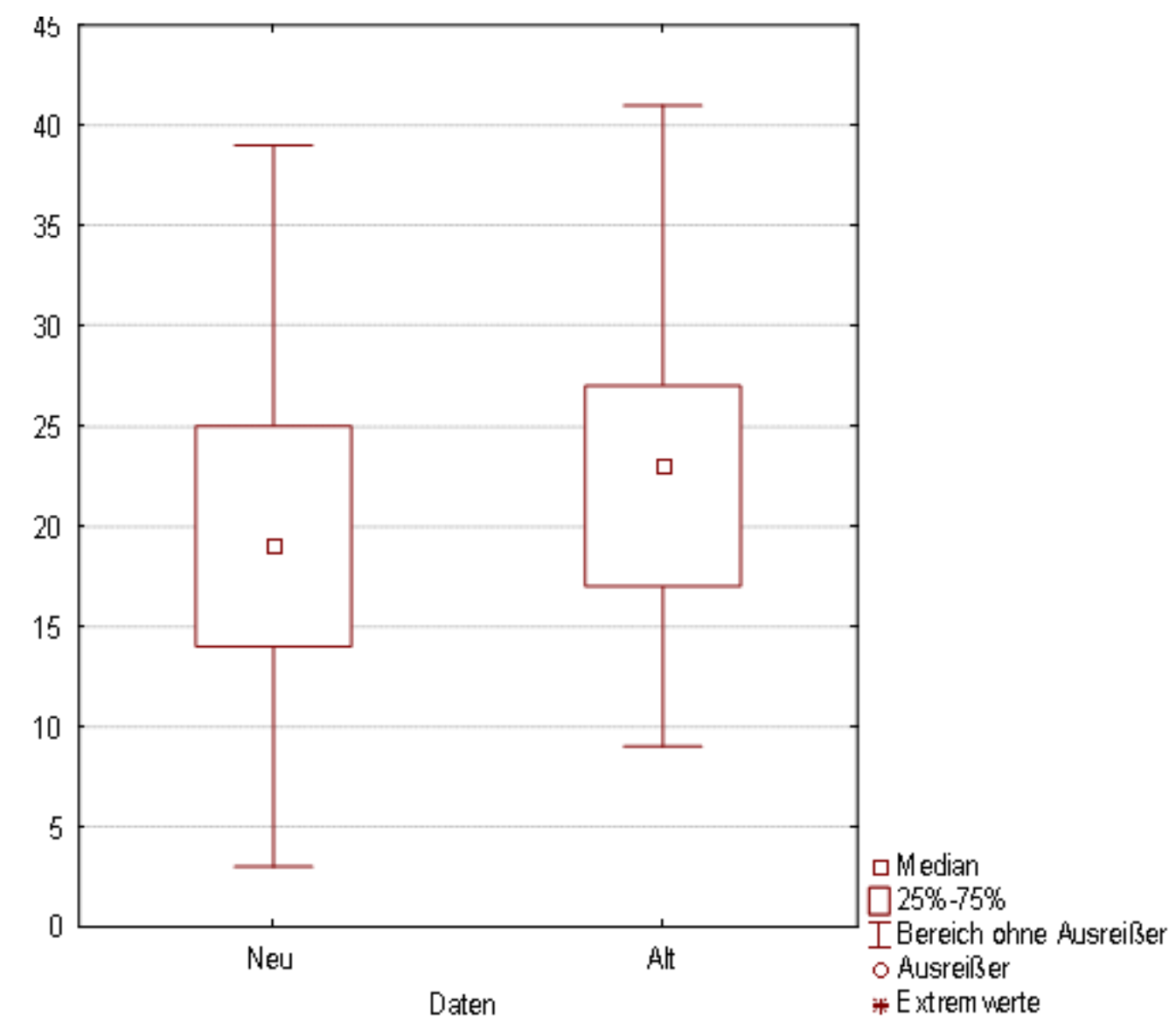

Abbildung 5: Vergleich des Altersdurchschnitts der aktuellen mit der historischen Gruppe

\subsection{Verlauf der Proteinurie vor und nach Therapiebeginn}

Da die Proteinurie als Marker der Nierenschädigung bei den AS-Patienten angesehen wird, sollte in diesem Test der Verlauf der Proteinurie unter ACE-Hemmern bei den 25 Patienten untersucht werden. Bei der Betrachtung der Proteinurie fällt auf, dass bei 56 Prozent (14 Patienten) die Proteinurie nach Einnahme der ACE-Hemmer sinkt. Bei 32 Prozent (acht Patienten) kommt es zu keiner Veränderung der Proteinurie. Die restlichen 12 Prozent (drei Patienten) verzeichnen eine Zunahme der Proteinurie unter ACE-Hemmern. 
In den nachstehenden Tabellen werden folgende Abkürzungen verwendet:

- Nummer = Kennzeichnung des Patienten

- Protein vor = Proteinurie in Gramm vor der Therapie mit ACE-Hemmern

- Protein nach $\quad=$ Proteinurie in Gramm nach der Therapie mit ACE-Hemmern

- Veränderungen $=$ Differenz der Proteinurie in Gramm vor und nach der

Therapie mit ACE-Hemmern

- MW = Mittelwert.

\begin{tabular}{|c|c|c|c|}
\hline Nummer & Protein vor & Protein nach & Veränderungen \\
\hline 23 & 11,80 & 5,00 & $-6,80$ \\
\hline 21 & 3,50 & 1,60 & $-1,90$ \\
\hline 30 & 2,39 & 1,10 & $-1,29$ \\
\hline 11 & 3,00 & 2,20 & $-0,80$ \\
\hline 12 & 1,95 & 1,60 & $-0,35$ \\
\hline 33 & 1,75 & 1,42 & $-0,33$ \\
\hline 8 & 0,42 & 0,23 & $-0,19$ \\
\hline 45 & 0,38 & 0,20 & $-0,18$ \\
\hline 6 & 0,18 & 0,05 & $-0,13$ \\
\hline 4 & 0,70 & 0,61 & $-0,09$ \\
\hline 3 & 1,58 & 1,50 & $-0,08$ \\
\hline 10 & 0,44 & 0,36 & $-0,08$ \\
\hline 7 & 0,44 & 0,40 & $-0,04$ \\
\hline 29 & 0,17 & 0,13 & $-0,04$ \\
\hline 1 & 0,03 & 0,03 & 0,00 \\
\hline 5 & 0,48 & 0,48 & 0,00 \\
\hline 13 & 1,60 & 1,60 & 0,00 \\
\hline 15 & 1,15 & 1,15 & 0,00 \\
\hline 19 & 0,40 & 0,40 & 0,00 \\
\hline 24 & 0,12 & 0,12 & 0,00 \\
\hline 27 & 0,20 & 0,20 & 0,00 \\
\hline 35 & 0,03 & 0,03 & 0,00 \\
\hline 51 & 0,79 & 0,95 & 0,17 \\
\hline 2 & 0,80 & 1,45 & 0,65 \\
\hline 9 & 2,00 & 4,30 & 2,30 \\
\hline MW & 1,45 & 1,08 & $-0,37$ \\
\hline
\end{tabular}

Tabelle 5: Verlauf der Proteinurie vor und nach Beginn der Therapie mit ACE-Hemmern 
Es zeigt sich, dass die Proteinurie unter der Therapie sowohl bei früher als auch später Einnahme des ACE-Hemmers sinkt. Durchschnittlich verringert sich die Proteinurie nach der Therapie von 1,45g auf 1,08g. Es kommt also zu einem signifikanten Sinken der Proteinurie nach der Therapie $(\mathrm{p}=0,02235)$, wie die folgende graphische Darstellung ebenfalls verdeutlicht.

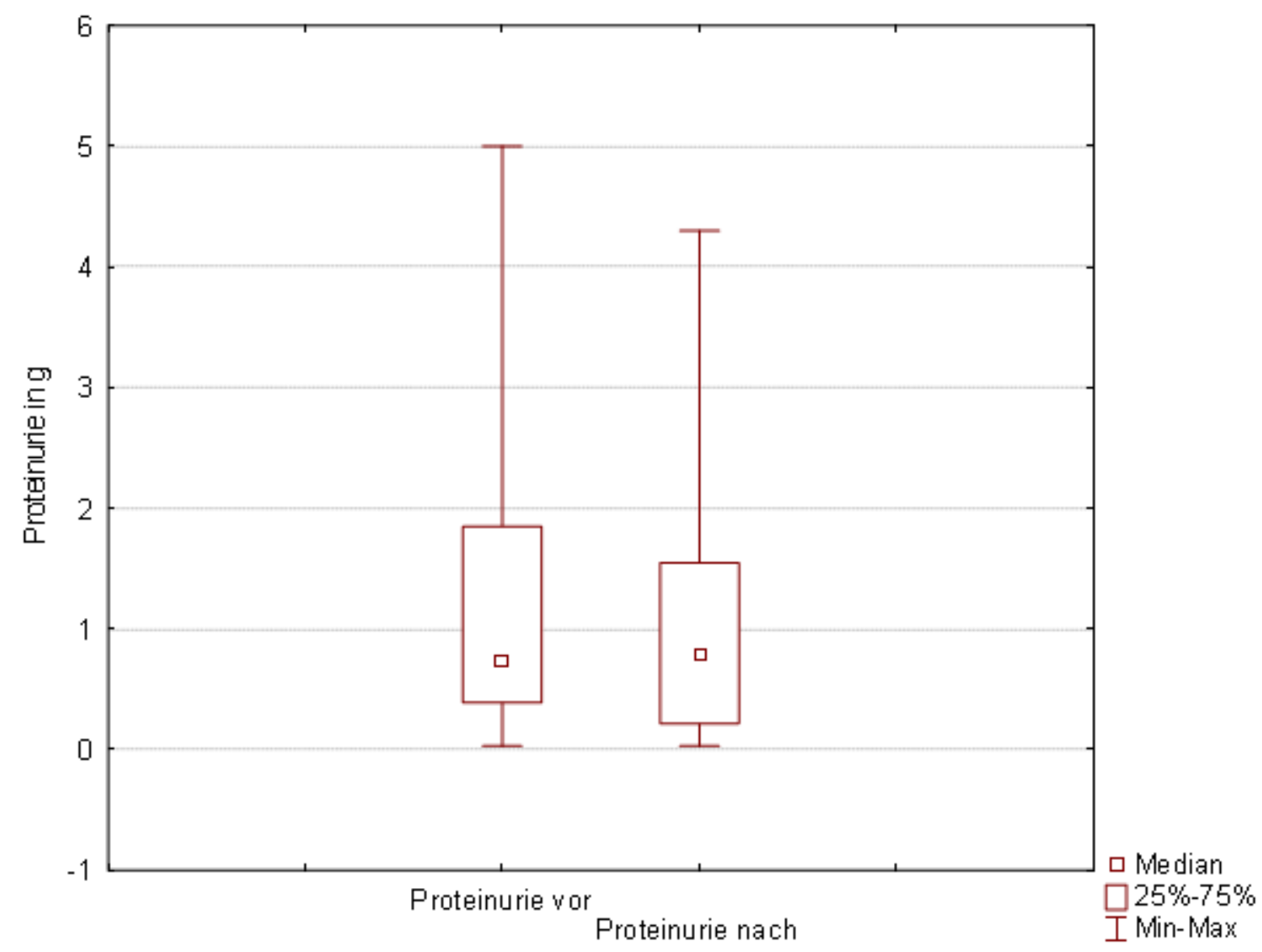

Abbildung 6: Verlauf der Proteinurie vor und nach Beginn der Therapie

\subsection{Darstellung eines möglichen Nutzens des Zeitpunktes der Therapie}

Bisher ist noch nicht geklärt, zu welchem Zeitpunkt die Einnahme von ACE-Hemmern bei AS-Patienten die beste Wirkung erzielt. In dieser Untersuchung wurde der Verlauf der Proteinurie bei Patienten mit früher Einnahme der ACE-Hemmer und der späten Einnahme 
verglichen. Sechs Patienten erhielten die ACE-Hemmer bei einer Proteinurie unter 0,2g. Bei zwei Patienten konnte damit die Proteinurie gesenkt werden. Vier Patienten zeigten keine Veränderung der Proteinurie.

In den nachstehenden Tabellen werden folgende Abkürzungen verwendet:

- Nummer

- ACE früh

- ACE spät

- Protein vor

- Protein nach

- Veränderungen

- MW
= Kennzeichnung des Patienten

$=$ ACE-Hemmer-Einnahme bei einem Proteinuriewert unter $0,2 \mathrm{~g}$

$=$ ACE-Hemmer-Einnahme bei einem Proteinuriewert über $0,2 \mathrm{~g}$

$=$ Proteinurie in Gramm vor der Therapie mit ACE-Hemmern

$=$ Proteinurie in Gramm nach der Therapie mit ACE-Hemmern

$=$ Differenz der Proteinurie in Gramm vor und nach der

Therapie mit ACE-Hemmern

$=$ Mittelwert.

\begin{tabular}{|c|c|c|c|c|}
\hline Nummer & ACE früh & Protein vor & Protein nach & Veränderung \\
\hline 6 & 1 & 0,18 & 0,05 & $-0,13$ \\
\hline 29 & 1 & 0,17 & 0,13 & $-0,04$ \\
\hline 1 & 1 & 0,03 & 0,03 & 0,00 \\
\hline 24 & 1 & 0,12 & 0,12 & 0,00 \\
\hline 27 & 1 & 0,20 & 0,20 & 0,00 \\
\hline 35 & 1 & 0,03 & 0,03 & 0,00 \\
\hline MW & & 0,12 & 0,09 & $-0,03$ \\
\hline
\end{tabular}

Tabelle 6: Verlauf der Proteinurie vor und nach Beginn der Therapie bei früher Einnahme

Bei 19 Patienten begann die Therapie bei einem Proteinuriewert von über 0,2g. Zwölf Patienten hatten nach der Therapie einen niedrigeren Proteinuriewert. Bei vier Patienten kam es zu keiner Veränderung, während bei drei die Proteinurie nach der Therapie anstieg. 


\begin{tabular}{|c|c|c|c|}
\hline Nummer & Protein vor & Protein nach & Veränderungen \\
\hline 23 & 11,80 & 5,00 & $-6,80$ \\
\hline 21 & 3,50 & 1,60 & $-1,90$ \\
\hline 30 & 2,39 & 1,10 & $-1,28$ \\
\hline 11 & 3,00 & 2,20 & $-0,80$ \\
\hline 12 & 1,95 & 1,60 & $-0,35$ \\
\hline 33 & 1,75 & 1,42 & $-0,33$ \\
\hline 8 & 0,42 & 0,23 & $-0,19$ \\
\hline 45 & 0,38 & 0,20 & $-0,16$ \\
\hline 4 & 0,70 & 0,61 & $-0,09$ \\
\hline 10 & 0,44 & 0,36 & $-0,08$ \\
\hline 3 & 1,58 & 1,50 & $-0,08$ \\
\hline 7 & 0,44 & 0,40 & $-0,04$ \\
\hline 19 & 0,40 & 0,40 & 0,00 \\
\hline 5 & 0,48 & 0,48 & 0,00 \\
\hline 15 & 1,15 & 1,15 & 0,00 \\
\hline 13 & 1,60 & 1,60 & 0,00 \\
\hline 51 & 0,79 & 0,95 & 0,16 \\
\hline 2 & 0,80 & 1,45 & 0,65 \\
\hline 9 & 2,00 & 4,30 & 2,30 \\
\hline MW & 1,87 & 1,40 & $-0,47$ \\
\hline & & & \\
\hline
\end{tabular}

Tabelle 7: Verlauf der Proteinurie vor und nach Beginn der Therapie bei später Einnahme

Die statistische Auswertung zeigt: Je früher der Beginn der Therapie gewählt wird, desto niedriger ist der Proteinuriewert. Patienten, die erst im späten Stadium des AS den ACEHemmer erhielten, begannen mit einem höheren Ausgangsproteinuriewert im Vergleich zu der Gruppe, die schon im frühen Stadium mit ACE-Hemmern behandelt wurde. Es liegt also ein signifikanter Unterschied zwischen der frühen und der späten Einnahme vor ( $\mathrm{p}=$ 0,00001). Jedoch kommt es zu keinem signifikanten Unterschied beim Verlauf der Proteinurie vor und nach Einnahme der ACE-Hemmer. Außerdem liegt keine Wechselwirkung zwischen früher und später Einnahme vor $(\mathrm{p}=0,35973)$. 
Dieses Ergebnis wird im Folgenden 95 Prozent-Konfidenzintervall graphisch näher veranschaulicht.

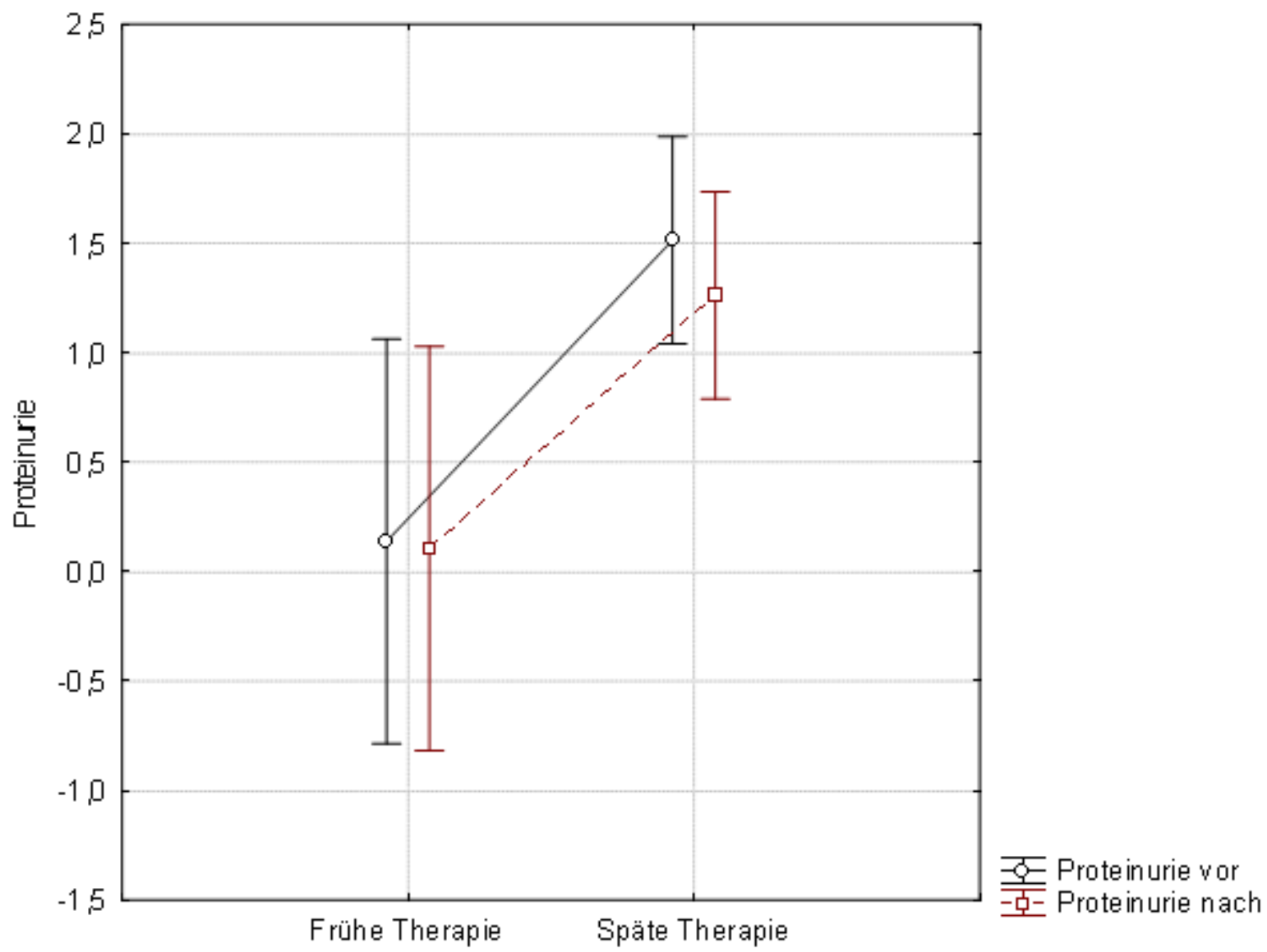

Abbildung 7: Verlauf der Proteinurie vor und nach Beginn der Therapie bei früher und später Einnahme

\subsection{Auswirkung des Alters während der Therapie}

In dieser Untersuchung sollten die unterschiedlichen Wirkungen der ACE-Hemmer abhängig vom Alter der Patienten dargestellt werden. Die Patienten wurden in zwei Altersgruppen unterteilt, die eine unter 20, die andere über 20 Jahre. Es wurde wiederum der Verlauf der Proteinurie durch die Therapie berücksichtigt.

13 Patienten gehörten zu der Gruppe der unter 20-Jährigen. Bei sieben Patienten (54 Prozent) kam es durch die Behandlung zu einem Sinken der Proteinurie. Bei vier (31 Prozent) blieb der Wert gleich und bei zwei Patienten (15 Prozent) stieg die Proteinurie. Durchschnittlich kam es 
zu einem Anstieg der Proteinurie um 0,07g. Grund dafür ist die Tatsache, dass es bei zwei Patienten zu einem durchschnittlich hohen Anstieg der Proteinurie kam.

Der niedrigste Proteinurieausgangswert lag bei den unter 20-Jährigen bei 0,03g, der höchste bei $2,39 \mathrm{~g}$, durchschnittlich bei $0,80 \mathrm{~g}$.

Die Proteinurie nach Therapiebeginn betrug durchschnittlich 0,87g. Der niedrigste Wert war $0,03 \mathrm{~g}$ und der höchste $4,3 \mathrm{~g}$.

In den nachstehenden Tabellen werden folgende Abkürzungen verwendet:

- Nummer

- Alter

- Protein vor

- Protein nach

- Veränderungen
$=$ Kennzeichnung des Patienten

$=$ Alter bei Erfassung der Daten

$=$ Proteinurie in Gramm vor der Therapie mit ACE-Hemmern

$=$ Proteinurie in Gramm nach der Therapie mit ACE-Hemmern

$=$ Differenz der Proteinurie in Gramm vor und nach der

Therapie mit ACE-Hemmern

$=$ Mittelwert.

\begin{tabular}{|c|c|c|c|c|}
\hline Nummer & Alter & Protein vor & Protein nach & Veränderungen \\
\hline 35 & 3 & 0,03 & 0,03 & 0,00 \\
\hline 27 & 6 & 0,20 & 0,20 & 0,00 \\
\hline 7 & 7 & 0,44 & 0,40 & $-0,04$ \\
\hline 6 & 8 & 0,18 & 0,05 & $-0,13$ \\
\hline 8 & 9 & 0,42 & 0,23 & $-0,19$ \\
\hline 29 & 13 & 0,17 & 0,13 & $-0,04$ \\
\hline 33 & 15 & 1,75 & 1,42 & $-0,33$ \\
\hline 3 & 16 & 1,58 & 1,50 & $-0,08$ \\
\hline 30 & 17 & 2,39 & 1,10 & $-1,29$ \\
\hline 5 & 18 & 0,48 & 0,48 & 0,00 \\
\hline 2 & 19 & 0,80 & 1,45 & 0,65 \\
\hline 1 & 19 & 0,03 & 0,03 & 0,00 \\
\hline 9 & 19 & 2,00 & 4,30 & 2,30 \\
\hline MW & 13 & 0,80 & 0,87 & 0,07 \\
\hline
\end{tabular}

Tabelle 8: Verlauf der Proteinurie vor und nach Beginn der Therapie der unter 20-Jährigen 
Zwölf Patienten des Registers waren über 20 Jahre alt. Bei sieben Patienten sank die Proteinurie während der Therapie. Bei vier Patienten blieb der Wert gleich und bei einem stieg die Proteinurie. Durchschnittlich kam es zu einem Sinken von 0,84g.

$0,4 \mathrm{~g}$ war der niedrigste und $11,8 \mathrm{~g}$ war der höchste Proteinurieausgangswert mit einem durchschnittlichen Wert von 2,15g.

Nach der ACE-Hemmer-Therapie lag der durchschnittliche Proteinuriewert bei 1,32g, der niedrigste war $0,2 \mathrm{~g}$ und der höchste Wert lag bei $5 \mathrm{~g}$.

\begin{tabular}{|c|c|c|c|c}
\hline Nummer: & Alter: & Protein vor: & Protein nach: & Veränderungen: \\
\hline 51 & 20 & 0,79 & 0,95 & 0,17 \\
\hline 4 & 21 & 0,70 & 0,61 & $-0,09$ \\
\hline 23 & 21 & 11,80 & 5,00 & $-6,80$ \\
\hline 10 & 22 & 0,44 & 0,36 & $-0,08$ \\
\hline 15 & 23 & 1,15 & 1,15 & 0,00 \\
\hline 13 & 24 & 1,60 & 1,60 & 0,00 \\
\hline 11 & 24 & 3,00 & 2,20 & $-0,80$ \\
\hline 12 & 25 & 1,95 & 1,60 & $-0,35$ \\
\hline 45 & 26 & 0,38 & 0,20 & $-0,18$ \\
\hline 24 & 31 & 0,12 & 0,12 & 0,00 \\
\hline 19 & 34 & 0,40 & 0,40 & 0,00 \\
\hline 21 & 39 & 3,50 & 1,60 & $-1,90$ \\
\hline MW & 25,83 & 2,15 & 1,32 & $-0,84$ \\
\hline
\end{tabular}

Tabelle 9: Verlauf der Proteinurie vor und nach Beginn der Therapie der über 20-Jährigen

Die statistische Auswertung zeigt bei Patienten, die bei Therapiebeginn über zwanzig Jahre alt waren, einen höheren Proteinurieausgangswert als bei den Patienten unter zwanzig Jahren. Die Patienten erreichen auch mit der Therapie nicht so niedrige Ausgangswerte der Proteinurie wie die unter 20-Jährigen. Jedoch liegt kein signifikanter Unterschied zwischen den unter 20- und den über 20-jährigen Patienten im Verlauf der Proteinurie vor $(\mathrm{p}=0,28169)$.

Der folgende Range Plot Graph soll dieses graphisch veranschaulichen. 


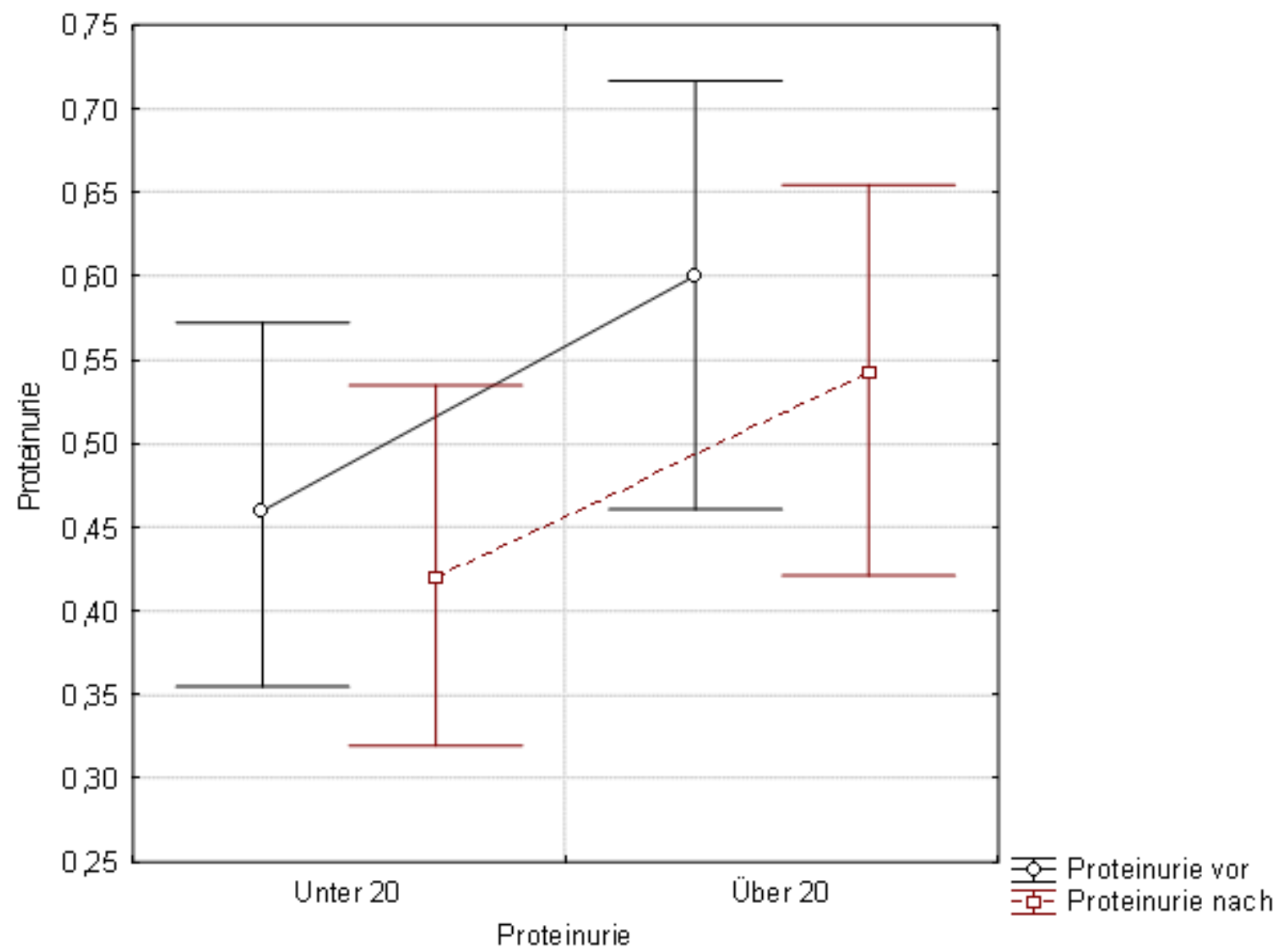

Abbildung 8: Verlauf der Proteinurie vor und nach Beginn der Therapie bei den unter und über 20jährigen Patienten 


\section{Diskussion}

In der vorliegenden Dissertation wird der Nutzen einer frühzeitigen ACE-Hemmer-Therapie bei AS-Patienten anhand eines Datenregisters dargestellt. Insgesamt 25 AS-Patienten wurden ins Register aufgenommen. Sie erhielten alle eine Therapie mit ACE-Hemmern. Sowohl vor als auch nach dem Beginn der Therapie wurden die Nierenfunktion und die Proteinurie der Patienten untersucht. Nach dem Beginn zeigte sich ein Rückgang der Proteinurie. Kein Patient erreichte das Stadium der Niereninsuffizienz. Es zeigte sich eine signifikante Assoziation zwischen der Einnahme der ACE-Hemmer und dem Rückgang der Proteinurie.

\subsection{Dialyseverzögerung durch ACE-Hemmer}

Beim AS kommt es durch die Mutation der $\alpha 3-$, $\alpha 4-$, oder $\alpha 5$-Kette des Kollagens IV zu einem veränderten Aufbau der GBM in der Niere, durch den sich eine chronische Entzündung der Niere entwickelt. Die Niere fibrosiert und die AS-Patienten erreichen das Endstadium, die terminale Niereninsuffizienz. Diese hat eine Dialyse oder Nierentransplantation zur Folge. In den letzten Jahren versagten die Nieren der AS-Patienten durchschnittlich im 20. Lebensjahr. In einem Tiermodell konnten Mäuse konstruiert werden, die das mutierte Gen enthielten. Diese Mäuse entwickelten ein AS, das in seinem Verlauf dem menschlichen AS ähnelt.

Man konnte in dem Modell belegen, dass durch eine prophylaktische Einnahme von ACEHemmern die Niereninsuffizienz um über 100 Prozent (zirka 15 Jahre auf den Menschen hochgerechnet) verzögert wird (Gross und Weber 2005b). Basierend auf den Erkenntnissen aus dem Tiermodell wurde in dieser Arbeit das Eintrittsalter der AS-Patienten in die Niereninsuffizienz unter ACE-Hemmer-Therapie untersucht. 25 Patienten sollten angeben, ob sie bereits dialysepflichtig sind. Die Angaben der Patienten aus dem aktuellen Register wurden mit den Daten nicht therapierter Patienten aus dem historischen Register verglichen, um verifizierte Aussagen über die Wirkung der ACE-Hemmer beim AS zu erhalten.

Da alle 25 untersuchten Patienten bereits eine ACE-Hemmer-Therapie bekommen hatten, konnte keine aktuelle Kontrollgruppe zur Untersuchung herangezogen werden. Es wurden deshalb Daten von AS-Patienten aus früheren Jahren genommen, um genauere Aussagen über die Wirkung von ACE-Hemmern auf die Verzögerung des Nierenversagens beim AS tätigen zu können. 
Beim historischen Register handelt es sich um 168 AS-Patienten, die das Stadium der Dialyse erreicht hatten. Der Altersdurchschnitt der Kontrollgruppe betrug 23 Jahre. Der Durchschnitt beim aktuellen Register betrug 19 Jahre. Kein Patient des aktuellen Registers hatte das Stadium des Nierenversagens erreicht.

Bei Betrachtung beider Boxplots erkennt man, dass beide bezüglich des Altersdurchschnitts schon jetzt auf einer Höhe liegen. Da aber der Boxplot der aktuellen im Vergleich zum Boxplot der historischen Daten beim Altersdurchschnitt noch in der Entwicklung steht, weil bisher kein Patient den Endpunkt Niereninsuffizienz erreicht hat, wird der Altersdurchschnitt beim Eintritt in die Dialyse aller aktuellen Patienten höher als bei der historischen Kontrollgruppe sein. Diese Annahme beruht auf der Tatsache, dass die Vielzahl der Patienten auch in den nächsten Jahren mit Hilfe der ACE-Hemmer-Therapie nicht dialysepflichtig sein wird, da diese Patienten noch eine gute Nierenfunktion aufweisen.

Man kann davon ausgehen, dass bei den Patienten mit einer ACE-Hemmer-Therapie der Altersdurchschnitt bei Eintritt der Dialyse weiter ansteigt. Schon jetzt sind 50 Prozent der therapierten Patienten zwischen 17 und 25 Jahre alt und werden das Stadium der Dialyse später als die aus den historischen Daten erreichen.

Ein erneuter Vergleich zwischen dem Eintrittsalter der Patienten dieser Dissertation und denjenigen aus der historischen Gruppe wäre sehr interessant, um die genaue Wirkung von ACE-Hemmern noch substantieller beurteilen zu können. Tendenziell zeigt sich aber bereits jetzt, dass durch die ACE-Hemmer-Therapie eine verbesserte Situation der Nierenfunktion für die AS-Patienten entstanden ist.

Die Ergebnisse aus dieser Arbeit sind mit dem Erfahrungen aus dem Mausmodell von Gross (2003a) vergleichbar. Das Modell imitierte den Phänotyp des AS im Zeitraffer von zehn Wochen. Es wurden 122 Mäuse in vier verschiedene Gruppen unterteilt. 56 Mäuse wurden nicht behandelt (Gruppe 1). 18 Mäuse bekamen eine späte ACE-Hemmer-Therapie bei einer Proteinurie von über 3g/l (Gruppe 2). Bei 24 Mäusen startete die Therapie in der vierten und endete in der zehnten Lebenswoche (Gruppe 3). Die übrigen 24 Mäuse bekamen die Therapie ebenfalls in der vierten Woche, jedoch wurde diese bis zum Tod der Mäuse durchgeführt (Gruppe 4).

Die Lebensdauer der unbehandelten Mäuse betrug durchschnittlich 71 Tage. Die Lebenserwartung der Mäuse der zweiten Gruppe stieg nur gering auf zirka 75 Tage, während die Lebenserwartung der Mäuse aus Gruppe drei fast 50 Prozent größer war (zirka 104 Tage). 
Bei der Gruppe 4 verbesserte sich die Lebenserwartung um über 100 Prozent. Diese Mäuse lebten durchschnittlich 150 Tage (Gross et al. 2003a). Das Ergebnis dieser Studie war, dass die Mäuse mit einer ACE-Hemmer-Therapie ein deutlich verzögertes Eintreten der Niereninsuffizienz vorweisen.

Unterstützt wird diese Erkenntnis durch die Veröffentlichung der „Effect of Strict blood pressure Control and $\mathrm{ACE}$ inhibition on the progression of chronic renal failure in Pediatric patients"(ESCAPE-Study); bei den in dieser Studie untersuchten Kindern konnte durch eine sechsmonatige Einnahme von einem ACE-Hemmer das Endstadium Dialyse hinausgezögert werden (Wühl et al. 2004).

Einen hinausgeschobenen Dialysebeginn belegt auch eine dreijährige Benazepril-Studie. 583 Patienten mit verschiedenen chronischen Nierenerkrankungen wurden untersucht. Alle Patienten wurden in zwei Gruppen unterteilt. Die eine Gruppe erhielt den ACE-Hemmer Benazepril, die andere ein Placebo. Nach drei Jahren hatten 31 Patienten in der Benazeprilund 57 in der Placebo-Gruppe das Endstadium erreicht ( $<$ 0.001). Das Risiko einer Dialyse reduzierte sich durch die Therapie mit Benazepril um 53 Prozent. Die Studie bewies, dass Benazepril einen Schutz gegen das Fortschreiten der Niereninsuffizienz bei Patienten mit verschiedenen Nierenerkrankungen bietet (Maschio et al. 1996).

Um ähnliche Ergebnisse aus dieser Arbeit für die AS-Patienten folgern zu können, sollte in einer weiterführenden Untersuchung eine aktuellere Kontrollgruppe generiert werden. Das Problem an der Aussagekraft des Registers dieser Arbeit liegt darin, dass keine aktuellere Kontrollgruppe untersucht werden konnte.

Bei der Generierung einer aktuellen Kontrollgruppe sollte man ähnlich wie in der BenazeprilStudie die Patienten in zwei Gruppen unterteilen. Die eine Gruppe erhält eine Therapie mit ACE-Hemmern, die andere nur eine Placebo-kontrollierte Medikation. Die Untersuchung sollte für die Teilnehmer beendet sein, sobald sie in das Stadium der Dialyse oder Nierentransplantation eintreten.

Nach einer vorgegebenen Untersuchungsdauer können beide Gruppen verglichen werden. Man sollte untersuchen, wann die nichttherapierten und therapierten Gruppen das Stadium der Niereninsuffizienz erreichen. Vor allem sollte der Altersdurchschnitt bei Eintritt der Dialyse verglichen werden, um genauere Angaben über den nephroprotektiven Effekt der ACEHemmer zu machen. 
Eine weitere Unsicherheit für eine eindeutige Beurteilung der Erkenntnisse aus dem aktuellen Register liegt in der Tatsache begründet, dass beim Vergleich mit den historischen Daten bis jetzt kein gemeinsamer Endpunkt vorliegt. Die historische Gruppe hat die Dialyse erreicht, die aktuelle noch nicht. Daher ist es schwierig, die beiden Gruppen statistisch zu vergleichen. Man kann in der derzeitigen Situation, in der noch keiner der aktuellen Patienten dialysepflichtig ist, nur tendenzielle Aussagen vornehmen.

Um eine genaues Ergebnis durch den Boxplotvergleich zu erhalten, müssen beide Gruppen nach dem Erreichen der terminalen Niereninsuffizienz der Patienten des aktuellen Registers erneut verglichen werden.

Außerdem haben die Auswertungen des aktuellen Registers nur über einen kurzen Beobachtungszeitraum der Patienten stattgefunden. Die REIN-Studie demonstrierte nämlich, dass die ACE-Hemmer-Therapie auch über einen längeren Zeitraum einen nephroprotektiven Effekt bei chronischen Nierenerkrankungen aufweist. Diese Studie untersuchte Patienten mit nicht diabetischen Nierenerkrankungen, in der ebenfalls in zwei Gruppen randomisiert wurde. Eine Gruppe erhielt eine ACE-Hemmer-Therapie, die andere nicht. Nach 60 Monaten wurde eine verminderte Inzidenz an Niereninsuffizienz bei den ACE-Hemmer-therapierten Patienten beobachtet. Nur 18 gegenüber 52 Prozent der Placebo-kontrollierte Patienten erreichten das Stadium der Niereninsuffizienz (Ruggenenti et al. 1999a). Ob diese Erkenntnisse der REINStudie auch auf die Therapie beim AS zutreffen, müssen zukünftige längerfristige Untersuchungen beurteilen.

In der vorliegenden Dissertation zeichnet sich die eindeutig erkennbare Tendenz ab, dass die ACE-Hemmer-Therapie auch bei AS-Patienten die Progression der Erkrankung verlangsamt. Die Arbeit bestätigt weiterhin die Vermutung aus den bereits durchgeführten Untersuchungen, dass durch eine ACE-Hemmer-Therapie das terminale Nierenversagen bei chronischen Nephropathien und speziell beim AS verzögert werden kann.

\subsection{Senkung der Proteinurie durch ACE-Hemmer}

Das Auftreten einer Proteinurie bei AS-Patienten signalisiert die voranschreitende Erkrankung und stellt damit eines ihrer Hauptsymptome dar. Schon in früheren, 20 Jahre andauernden Studien wurde die Proteinurie als ein entscheidender Risikofaktor für Niereninsuffizienz und renale Mortalität erkannt (Tarver- Carr et al. 2000). Das Ausmaß der 
Proteinurie scheint mit der Größe des Nierenschadens zu korrelieren. Eine medikamentöse Reduzierung der Proteinurie hilft die Nierenfunktion länger zu erhalten (Abbate et al. 1999). Durch die verringerte Ausscheidung von Eiweißen kann die resultierende Freisetzung von chemotaktischen Substanzen und profibrotischen Zytokinen unterdrückt werden, die eine Entzündung im Tubulointerstitium mit anschließender tubulointerstitieller Fibrose verursacht (Wenzel und Wolf 2003).

Zunächst deuteten Studien zur Wirkung von ACE-Hemmern bei diabetischer Nephropathie darauf hin, dass ACE-Hemmer einen sehr großen antiproteinurischen und antifibrotischen Effekt aufweisen (Lewis et al. 1993). Es wurde erkannt, dass chronische Niereninsuffizienzen unabhängig von der Ursache nach dem gleichen Schema ablaufen:

Hypertension $\rightarrow$ Anstieg des glomerulären Drucks $\rightarrow$ erhöhte Permeabilität $\rightarrow$ Proteinurie $\rightarrow$ interstielle Entzündung $\rightarrow$ Vernarbung.

Weitere Studien über den Nutzen der ACE-Hemmer bei nichtdiabetischen Nephropathien zeigten einen positiven Nutzen von ACE-Hemmern auf die verzögerte Abnahme der glomerulären Filtrationsrate und einen verzögerten Anstieg der Proteinurie (The Gisen Group 1997)

Diese These wurde nochmals durch die REIN-Studie bestätigt (Ruggenenti et al. 1998). Sie konnte den Nachweis über den Effekt der ACE-Hemmer erbringen und beweisen, dass die Behandlung mit ACE-Hemmern eine Verringerung der Proteinurie mit einem nierenprotektivem Effekt bewirkt (Ruggenenti et al. 1998).

Außerdem bekräftigte die ESCAPE-Study die Wirkung der ACE-Hemmer bei hypertensiven Kindern mit Nephropathien und konnte den Effekt von ACE-Hemmern auf die Senkung der Proteinurie (zirka 50 Prozent) unterstreichen (Wühl et al. 2004).

Die Studie an den COL4A3-Mäusen zeigte, dass der ACE-Hemmer diesen Effekt auch bei AS- Patienten aufweist. Wie beschrieben imitierte das Mausmodell den Phänotyp des AS im Zeitraffer von zehn Wochen. Bei den mit ACE-Hemmern behandelten Mäusen kam es im Vergleich zu den nicht behandelten Mäusen zu einem deutlich verzögerten Eintritt der Proteinurie. Bei den unbehandelten Mäusen entwickelte sich eine Proteinurie in der sechsten Woche. Die frühtherapierten Mäuse zeigten erst zwei Wochen später Symptome einer Proteinurie (Gross und Weber 2005b).

Proesmans und Van Dyck (2004) untersuchten die Wirkung der ACE-Hemmer bei zehn pädiatrischen AS-Patienten, die fünf Jahre eine Therapie mit dem ACE-Hemmer Enalapril 
erhielten. Auch hier konnte mit ACE-Hemmern das Ausmaß der Proteinrie gesenkt werden. Vor Beginn der Therapie betrug die mediane Urinproteinurie 1,58 g. Die Proteinurie verringerte sich auf $0,98 \mathrm{~g}$ nach einem Jahr, 1,09g nach zwei, 1,35g nach drei, 1,11g nach vier und 1,38g nach fünf Jahren (Proesmans und Van Dyck 2004).

Die Aussagen der genannten Studien entsprechen den Erkenntnissen dieser Dissertation. Bei dem untersuchten Verlauf der Proteinurie zeigt sich, dass die Proteinurie durch eine ACEHemmer-Behandlung gesenkt werden kann. In der Gesamtbetrachtung aller Patienten des aktuellen Registers konnte eine Senkung der Proteinurie festgestellt werden. Es kam zu einem signifikanten Sinken der Proteinurie nach der Therapie $(p=0,02235)$. Im Durchschnitt sank die Proteinurie um 0,37g.

Bei 14 der 25 Patienten wurde die Proteinurie durch die ACE-Hemmer-Therapie gesenkt. Bei acht Patienten verschlechterte sich die Proteinurie nicht und stagnierte beim gleichen Wert wie vor Therapiebeginn. Bei drei Patienten stieg der Proteinuriewert trotz Therapie an.

Um einen noch genaueren Aufschluss über die Wirksamkeit der ACE-Hemmer auf den Verlauf der Proteinurie bei dem AS zu erhalten, bietet sich auch hier eine Placebokontrollierte Untersuchung an. Da die Höhe der Proteinuriewerte und die glomeruläre Filtrationsrate einen verlässlichen Aussagewert über den Funktionszustand der Nieren geben, sollten diese Werte in weiteren Untersuchungen zu vorher festgeschriebenen Zeitpunkten aller Patienten bestimmt werden, zum Beispiel Proteinuriewert vor Therapiebeginn und wiederholend nach sechs Monaten.

Denn hier ist das aktuelle Datenregister nicht aussagekräftig genug. Bei der Erstellung des Registers wurden die Fragebogen der einzelnen Patienten mit den Arztbriefen ausgewertet. Jedoch sind die Zeitpunkte der Bestimmung der Nierenfunktionsparameter wie Proteinurie nicht bei allen Patienten gleich. Es konnte zum Beispiel nicht eindeutig bestimmt werden, wann und $\mathrm{zu}$ welchem Zeitpunkt der erste Proteinuriewert nach Beginn der Therapie gemessen wurde.

Unter der Berücksichtigung der Erkenntnisse der vorangegangenen Studien kann man indes davon ausgehen, dass die Patienten aus diesem Register von der verringerten Ausscheidung der Proteinurie profitieren werden. Denn vor allem die nephrotoxische Auswirkung der Proteinurie auf die Niere, die auf lange Sicht zur Vernarbung führt, kann unterdrückt werden. Es besteht damit die Hoffnung, dass die Dialyse beim AS um Jahre hinausgezögert wird. 
Um dieses Ergebnis weiterhin zu bekräftigen, sollte das Ausmaß der Proteinurie bei den 25 Patienten auch zukünftig beobachtet werden. Da es sich beim AS um eine voranschreitende ernste Erkrankung handelt, kann vor allem die Frage, wie lange die Proteinurie durch die ACE-Hemmer-Therapie gesenkt werden kann, erst in einigen Jahren genau beantwortet werden. Da auch andere Studien eine enge Korrelation zwischen dem Ausmaß der Proteinurie und der Abnahme der GFR vermuten, sollte bei den zukünftigen Untersuchungen vermehrt ein Augenmerk auf die GFR gelegt werden (Rossing et al.1993). Leider waren die Angaben der GFR-Werte in dem Register dieser Dissertation zu gering, um schon hier statistische Tendenzen darzustellen.

Durch die Therapie mit ACE-Hemmern kann man zwar die Progression des AS bremsen, die Mechanismen der chronischen Nierenschädigung aber nicht vollständig blockieren (Wolf 2005). Trotzdem scheint die Behandlung mit ACE-Hemmern bei AS-Patienten die Proteinurie $\mathrm{zu}$ senken und damit sehr nützlich $\mathrm{zu}$ sein. Daten aus früheren Untersuchungen geben Hinweise, dass eine exzessive Proteinurie ein Faktor sein kann, Strukturen der Niere zu verletzen und damit eine Glomerulosklerose zu verursachen (Abbate et al. 2002).

\subsection{Nutzen eines frühen gegenüber späten Therapiebeginns mit ACE-Hemmern}

Wie beschrieben handelt sich beim AS um eine vererbte Erkrankung, bei der Patienten von Geburt an betroffen sind. Jedoch nimmt die Schwere der Symptome erst im Verlauf der Erkrankung zu. Man kann diesbezüglich das AS in vier Phasen unterteilen. Zu Beginn zeigen sich eine Hämaturie und Proteinurie. Mit zunehmenden Veränderungen im Aufbau der Nieren entsteht eine Glomerulosklerose, die sich bis zu einer Fibrosierung des Tubulointerstitiums ausbreitet. Am Ende steht die terminale Niereninsuffizienz.

Im Rahmen dieser Dissertation wurde untersucht, ob eine frühzeitige Einnahme der ACEHemmer eine bessere Wirkung als eine späte Einnahme zeigt.

Eine Hypothese ist, dass das AS länger in den frühen Phasen verbleibt, je früher mit der Therapie begonnen wird. Bis jetzt ist eine Heilung des AS nicht möglich. Das Ziel der Therapie sollte jedoch sein, die AS-Patienten so lange wie möglich in den ersten beiden Phasen des AS zu halten (Kashtan 2005). 
Als eine frühzeitige Einnahme wurden in dieser Arbeit alle Patienten definiert, deren Proteinuriewert vor der Therapie bei unter $0,2 \mathrm{~g}$ pro 24 Stunden lag. Bei später Einnahme betrug die Proteinurie über $0,2 \mathrm{~g}$.

In dem aktuellen Datenregister fiel auf, dass bei den Patienten, die zu einem späteren Zeitpunkt mit der Therapie begannen, der Proteinurieausgangswert deutlich höher war. Die Proteinurie der spättherapierten Patienten konnte auch nach der Therapie nicht mehr so weit wie bei den frühtherapierten Patienten gesenkt werden. Zusammen mit den Erkenntnissen aus früheren Studien lässt sich sagen, dass die spättherapierten Patienten aufgrund des höheren Proteinuriewertes bereits eine eingeschränktere Nierenfunktion aufweisen als die frühtherapierten Patienten (Tarver-Carr et al. 2000).

Es scheint, dass eine erhöhte Proteinurie eine Fibrosierung begünstigt. Die Proteinurie verursacht über die Freisetzung von chemotaktischen Substanzen und profibrotischen Zytokinen eine Entzündung im Tubulointerstitium mit anschließender tubulointerstitieller Fibrose (Wenzel und Wolf 2003).

Vor allem die Ergebnisse aus den Mausmodellen deuten daraufhin, dass die Überlebensrate der Mäuse deutlich besser war, je früher mit der Therapie begonnen wurde. Zwar konnte die Proteinurie sowohl bei den früh- als auch spättherapierten Mäusen reduziert werden, jedoch war die Lebensdauer bei den frühtherapierten doppelt so lange wie bei den spättherapierten Mäusen (Gross et al. 2003a). Die antiproteinurischen Wirkungen bei der späten Therapie bewiesen also keine verlängerte Lebenserwartung der Mäuse. Es wird angenommen, dass bei der späten Therapie bereits eine Proteinurie vorlag und diese nicht mehr durch ACE-Hemmer beseitigt werden konnte. Diese Proteinurie sorgte bei den spättherapierten Patienten zu irreversiblen Umstrukturierungen der Niere (Gross et al. 2004).

Der nephroprotektive Effekt war in dieser Mausmodellstudie stark vom Zeitpunkt des Therapiebeginns abhängig (Gross und Weber 2005b). Es bleibt unklar, warum die frühe Therapie die Lebenserwartung der Mäuse erhöht. Die Erkenntnisse aus der Studie besagen, dass eine durchgehende Behandlung mit ACE-Hemmern vor Eintritt einer Proteinurie den größten Nutzen aufweist (Gross und Kashtan 2009).

Diese Theorie unterstützt die „Modification of Diet in Renal Disease Studie“ (MDRD: Klahr et al. 1994). Sie erkannte, dass Patienten mit Proteinuriewerten unter $1 \mathrm{~g} / \mathrm{d}$ mehr unter einer ACE-Hemmer-Therapie profitieren als Patienten über 1g/d. Es wurde vermutet, dass Patienten in einem weniger fortgeschrittenen Stadium der Nierenfunktionsstörung auch einen 
niedrigeren Blutdruck aufweisen. Je niedriger der Blutdruck war, desto stärker war eine Reduktion der Proteinurie zu erkennen (Klahr et al. 1994).

Es ist denkbar, dass die Patienten mit höheren Proteinuriewerten eine schlechtere Prognose bezüglich ihrer Nierenfunktion haben, jedoch durch die Therapie das Ausmaß der Proteinurie bei den spättherapierten Patienten vermehrt gesenkt werden kann. Diese These unterstützen die Erkenntnisse der REIN-Studie. Die Wirkung der ACE-Hemmer war bei dieser Studie umso größer, je höher der Proteinurieausgangswert war (Ruggenenti et al. 1999b).

Im Vergleich dazu steht die Vermutung, dass hohe Proteinuriewerte die Fibrose der Nieren begünstigen. Das spricht für einen frühen Therapiebeginn mit ACE-Hemmern. Ferner haben weitere Studien bewiesen, dass unter einer ACE-Hemmer-Behandlung der intraglomeruläre Druck reduziert wird. Das wirkt ebenfalls einer Fibrosierung der Niere entgegen (Zatz et al. 1986).

In dem aktuellen Register dieser Arbeit kann jedoch keine eindeutige Aussage über den Verlauf der Proteinurie bei früh- gegenüber spättherapierten Patienten gemacht werden. Es zeigt sich kein signifikanter Unterschied im Verlauf der Proteinurie vor und nach Einnahme der ACE-Hemmer. Ein möglicher Grund kann die unterschiedliche Anzahl der Patienten in den beiden untersuchten Gruppen sein. Von den 25 Patienten bekamen nur sechs eine frühe Therapie, während alle anderen mit einer späten Therapie behandelt wurden.

Um Aufschluss über einen unterschiedlichen Effekt zwischen früher oder später Einnahme zu erhalten, sollten in einer fortführenden Untersuchung zwei gleich große Gruppen länger untersucht und mit gleicher Anzahl an AS-Patienten generiert werden. Die eine Gruppe erhält die Therapie bei einem Proteinuriewert unter $0,2 \mathrm{~g}$, die andere bei über 0,2 g. Nach einem festgelegten Zeitpunkt sollten beide Gruppen hinsichtlich ihres Verlaufes der Proteinurie verglichen werden.

Interessant wäre die Beantwortung der Frage, wie lange bei frühtherapierten Patienten die Proteinurieausgangswerte niedrig gehalten und eine Progression des AS verzögert werden.

Zusätzlich sollte erkannt werden, ob die frühtherapierten Patienten aufgrund der langen Therapiedauer eher zu Nebenwirkungen durch die ACE-Hemmer neigen. In dem Datenregister zeigte kein Patient irgendwelche Nebenwirkungen auf die Einnahme von ACEHemmern. 
Ähnlich wie die Erkenntnisse aus früheren Untersuchungen, in denen eine erhöhte Proteinurie eine Nierenschädigung begünstigt, weisen die Ergebnisse dieser Arbeit auf einen frühen Therapiebeginn beim AS hin, um die Proteinuriewerte niedrig zu halten.

\subsection{Bedeutung des Alters während der Therapie mit ACE- Hemmern}

Im Zusammenhang mit den bereits beschriebenen Überlegungen, dass das AS eine voranschreitende Erkrankung darstellt und mit zunehmendem Alter der Patienten die Schwere der Symptome zunimmt, wurden in dem Datenregister dieser Arbeit mögliche unterschiedliche Auswirkungen der ACE-Hemmer bei Patienten unter und über 20 Jahren untersucht.

Ähnlich wie bei den früh- gegenüber spättherapierten Patienten zeigen sich unterschiedliche Proteinurieausgangswerte. Bei Patienten, die bei Therapiebeginn über zwanzig Jahre alt waren, ist der Proteinurieausgangswert (Durchschnittswert: 2,15g) höher als bei den unter 20-Jährigen (Durchschnittswert: 0,80g). Die über 20 Jahre alten Patienten erreichen auch mit der Therapie nicht mehr so niedrige Proteinuriewerte (Durchschnitt: 1,32g) wie die unter 20Jährigen (Durchschnitt: 0,87g). Jedoch liegt kein signifikanter Unterschied zwischen den unter und über 20 Jahre alten Patienten bei der Senkung der Proteinurie durch ACE-Hemmer vor $(\mathrm{p}=0,28169)$. Deshalb sind auch hier weitere Untersuchungen notwendig, um genauere Aufschlüsse über die Bedeutung des Alters während der Therapie zu erhalten.

Man kann aber bei den unter 20-jährigen Patienten ähnliche Ergebnisse wie bei den bereits oben beschriebenen Frühtherapierten erwarten. Es ist anzunehmen, dass bei den jungen Patienten das AS noch nicht so weit fortgeschritten ist. Deshalb sollte die Therapie schon in jungen Jahren begonnen werden, um eine bessere Nierenfunktion länger beizubehalten. Beim AS kommt es durch den veränderten Aufbau der GBM zu einer Veränderung der Homöostase der Kapillaren im Glomerulus. Diese nimmt mit zunehmendem Alter zu, es entwickeln sich Umstrukturierungen in den Nieren (Kashtan 2004).

Diese Umstrukturierungen der GBM bewirken vermutlich auch, dass einige Nephrone geschädigt und funktionsuntüchtig werden. Die noch intakten Nephrone übernehmen die Aufgaben der geschädigten Nephrone, um den Ausfall zu kompensieren. Dadurch kann es längerfristig zu einer Überforderung der noch intakten Nephronen durch eine Hyperfiltration 
kommen. Durch die Kompensation entwickelt sich bei den nicht geschädigten Nephronen eine Hyperperfusion und -filtration der Glomeruli mit erhöhtem Druck im Glomerulus (Wolf 2005).

Druckerhöhungen sowie aktive Wachstumsvorgänge wie Proliferation von Mesangiumzellen, aber auch Hypertrophie von Tubuluszellen vergrößern die noch intakten Nephrone. Die Anpassung der Nephrone an die neue Situation kann längerfristig zu irreversiblen Nierenschädigungen führen (Brenner 1985). Es entsteht eine Glomerulosklerose, die in früher Kindheit durch eine ACE-Hemmer-Therapie mutmaßlich aufgehalten oder zumindest verzögert werden kann. Ein vermehrtes Auftreten von Myofibroblasten und eine Proliferation des Mesangiums, die Vorboten einer interstitiellen Fibrose darstellen, können durch eine Therapie gebremst werden. So kann auch ein frühzeitiger Therapiebeginn eine Zerstörung der Podozytenfußfortsätze verhindern.

Diese erkennbaren Erscheinungen weisen darauf hin, dass beim AS die ACE-HemmerTherapie schon in frühem Kindesalter angewendet werden sollte.

\subsection{Ausblick}

Die Ergebnisse der Dissertation zeigen erfreulicherweise, dass keiner der 25 Patienten unter der Therapie mit ACE-Hemmern das Stadium des terminalen Nierenversagens erreicht hat. Es ist anzunehmen, dass die frühzeitige Behandlung mit ACE-Hemmern auch beim AS effektiv ist. Während der Therapie kam es bei den meisten Patienten zum Sinken der Proteinurie ohne Nebenwirkungen. Es ist notwendig, die Patienten-Daten in den nächsten Jahren weiter zu beobachten. Der Zeitraum dieser Untersuchungen war für den Verlauf des AS zu kurz, um eindeutige Aussagen über das Ausmaß der ACE-Hemmer zu machen. Es ist empfehlenswert, den Zustand und die Nierenfunktionsparameter der Patienten regelmäßig zu verfolgen.

In einer fortführenden Untersuchung sollte zusätzlich eine aktuelle Kontrollgruppe konstruiert werden, die keine Behandlung mit ACE-Hemmern erhält. Der Krankheitsverlauf zwischen den therapierten und nichttherapierten Patienten sollte für einen längeren Zeitraum beobachtet werden.

Zusätzlich sollte eine einheitliche Abfrage der Nierenfunktionsparameter erfolgen. Es bietet sich an, an einem jährlich festgelegten Zeitraum eine mögliche Dialysepflichtigkeit sowie den Proteinuriewert zu erfragen. Dadurch könnte auch die Wirkung der ACE-Hemmer genauer 
geklärt werden wie zum Beispiel, ob ein früher oder ein später Therapiebeginn sinnvoller wäre. Diese Fragestellung soll die Placebo-kontrollierte, randomisierte EARLY-PROTECTAlport-Studie mit Ramipril beantworten, die deutschlandweit ab Herbst 2011 durchgeführt wird. 


\section{Zusammenfassung}

Das Alport-Syndrom (AS) stellt eine hereditäre und progrediente Nierenerkrankung dar. Bei dem Syndrom handelt es sich um eine Glomerulopathie, die sich durch eine Mutation der Gene COL4A3, COL4A4 oder COL4A5 entwickelt (Kashtan 2007). Diese Gene kodieren für das Kollagen IV. Die Mutation eines Gens führt zu einem veränderten Aufbau des KollagenIV-Moleküls, die wiederum den Aufbau der glomerulären Basalmembran verändert. Die eigentliche Filtrationsbarriere für Eiweiße geht dadurch verloren (Netzer et al. 1997).

Es kommt zu einer chronischen Entzündung und damit zu einer Fibrose der Niere. Bei einigen AS-Patienten wird die Nephropathie von einer Innenohrschwerhörigkeit und Sehschwäche begleitet. Durch die Vernarbung der Niere entsteht allmählich eine Niereninsuffizienz.

Bisherige Untersuchungen haben eine Wirkung bei chronischen Nephropathien durch ACEHemmer erkannt und festgestellt, dass auch AS-Patienten von einer Therapie mit ACEHemmern profitieren können. Obwohl der genaue Mechanismus der Wirkung von ACEHemmern beim AS noch unbekannt ist, lassen Versuche an Tiermodellen vermuten, dass durch eine Unterdrückung der Zytokine sowie der Kollagenproduktion durch die Podozyten sowie antifibrotische und antiinflammatorische Effekte die Progression der Erkrankung verlangsamt wird. Dadurch kann das Stadium des terminalen Nierenversagens verzögert werden.

Eine retrospektive Untersuchung, an der 25 AS-Patienten teilnahmen, hat den möglichen Einfluss von ACE-Hemmern bei AS-Patienten auf die Verzögerung der Niereninsuffizienz bestätigt. Das in der Dissertation erarbeitete Datenregister mit Hilfe deutscher AS-Patienten stellt einen Teil eines europäischen Registers dar, das Daten von AS-Patienten europaweit zusammenfasst und die Wirkung und Nebenwirkungen der ACE-Hemmer dokumentiert.

Da es bis jetzt keine offizielle Zulassung für die Einnahme von ACE-Hemmern bei ASPatienten gibt, könnte durch eine Bestätigung der Wirkung der ACE-Hemmer eine Therapieempfehlung ausgegeben werden.

Im Rahmen der vorliegenden Dissertation sollten AS-Patienten jeweils einen Fragebogen ausfüllen und Angaben über den Verlauf ihrer Erkrankung machen. Besonders wurde ein möglicher Eintritt der Patienten in das Stadium der Niereninsuffizienz und der Verlauf der Proteinurie während der Therapie betrachtet. 
Keiner der 25 mit einem mittleren Alter von 19 Jahren therapierten Patienten hat während der Untersuchung das Stadium der Niereninsuffizienz erreicht. Eine vergleichbare historische Gruppe erreichte das Stadium der terminalen Niereninsuffizienz im Durchschnitt mit 23 Jahren. Dieser verzögerte Eintritt der terminalen Niereninsuffizienz kann als Folge der Einnahme der ACE-Hemmer angesehen werden. Diese Annahme bestätigt ein verlangsamtes Einsetzen der Niereninsuffizienz beim AS, somit eine verzögerte Abhängigkeit von der Dialyse oder Nierentransplantation.

Es bleibt indes unklar, in welchem Alter die Niereninsuffizienz bei AS-Patienten eintritt. In einer weiteren Untersuchung sollte daher das Eintrittsalter der Patienten in die Niereninsuffizienz genauer untersucht werden.

In dieser Dissertation konnte ein signifikantes Abnehmen der Proteinurie nach dem Therapiebeginn festgestellt werden. Ob der Beginn im frühen oder späten Stadium der Erkrankung nützt, konnte leider nicht eindeutig belegt werden. Man kann aber sagen, dass der Proteinurieausgangswert bei den Patienten im späten Stadium des AS deutlich höher ist als im frühen Stadium. Eine frühzeitige Therapie mit ACE-Hemmern ist deshalb zu empfehlen.

Es scheint bestätigt, dass die ACE-Hemmer kurzfristig auf die Proteinurie und längerfristig auf die Verzögerung der Niereninsuffizienz wirken.

Die Ergebnisse dieser Arbeit und weitere Untersuchungen geben die Hoffnung, dass durch einen frühen Einsatz von ACE-Hemmern bereits im Frühstadium des AS die Niereninsuffizienz um Jahre verzögert werden kann.

Mit Hilfe der Ergebnisse dieser Arbeit konnte eine Placebo-kontrollierte, randomisierte Alport-Studie entwickelt werden, die ab Herbst 2011 deutschlandweit durchgeführt wird und weitere Erkenntnisse über die Wirkung der ACE-Hemmer beim AS geben soll. 


\section{Anhang: Fragebogen}

\section{Angaben zur Person oder zum Indexpatienten}

Name:

Vorname:

Geburtsdatum:

Geschlecht:

Staatsangehörigkeit:

Größe und Gewicht:

Identifikationsnummer:

Betreuendes/einsendendes Zentrum/Arztstempel:

Datum:

\section{Familienanamnese}

1.1 X-chromosomale Vererbung

$\square \mathrm{ja}$

ggf. bitte hier Stammbaum aufmalen

$\square$ wahrscheinlich

1.2 Autosomale Vererbung

$\square$ ja

$\square$ wahrscheinlich

1.3 Vererbungsmodus nicht bekannt

$\square$ keine Familiendaten vorhanden

$\square$ einzelner Patient

\subsection{Vererbungsmodus ist bekannt}

Wer in Ihrer Familie ist/war betroffen (oder Stammbaum), und welche Symptome (Schwerhörigkeit, Augenveränderungen, Nierenbeteiligung, Leiomyomatose)? 
○1.) -4.)

○2.) ( 5 ()

○) ( $\quad$ (6.)

1.4.1 Wann wurde die Diagnose Alport-Syndrom Ihres/lhrer Familienangehörigen gestellt?
०1.)
4.)
-2.)
○.)
$\circ 3$.
$\circ 6$.

1.4.2 Ist/war Ihr(e) Familienangehörige(r) dialysepflichtig, und wenn ja, in welchem Alter?
०1.)
$\circ 4$.
०2.)
○.)
○3.)
$\circ 6$.

\section{Personenbezogene Angaben des Patienten}

\subsection{Seit wann ist die Diagnose Alportsyndrom bei Ihnen bekannt?}

2.2 Ist bei Ihnen eine Nierenbiopsie durchgeführt worden?

$\square$ ja, wenn ja, in welchem Alter und mit welchem Ergebnis (ggf. Befund beifügen)

$\square$ nein

$\underline{2.3 \text { Ist bei Ihnen eine genetische Diagnostik / Mutationsanalyse erfolgt? }}$

$\square$ ja, wenn ja, in welchem Alter und mit welchem Ergebnis (ggf. Befund beifügen)

$\square$ nein

\section{Klinische Daten und Verlaufsparameter}


3.1 Welche Medikamente (bitte alle angeben) nehmen Sie ein und ab welchem Alter?

$\begin{array}{lll}\rightarrow \text { Alter: } & \circ & \rightarrow \text { Alter: } \\ \rightarrow \text { Alter: } & \circ & \rightarrow \text { Alter: } \\ \rightarrow \text { Alter: } & \circ & \rightarrow \text { Alter: } \\ \rightarrow \text { Alter: } & \circ & \rightarrow \text { Alter: } \\ \rightarrow \text { Alter: } & \circ & \rightarrow \text { Alter: }\end{array}$

3.2 Nehmen Sie Cyclosporin?

$\square$ ja

$\square$ nein

3.3 Werden Sie mit ACE-Hemmern therapiert?

$\square$ ja, wenn ja, welcher Medikamentenname und ab welchem Alter:

$\square$ nein

4. Symptome (wir bitten Sie um möglichst genaue Angaben)

\subsection{Nierenerkrankung}

4.1.1 Proteinurie (in g pro 24 Stunden oder in mg pro Deziliter)

- vor Therapiebeginn:

- nach Therapiebeginn:

$\circ$ im weiteren Verlauf:

$\underline{4.1 .2 ~ K r e a t i n i n ~(i n ~ m g ~ p r o ~ D e z i l i t e r) ~}$

- vor Therapiebeginn:

- nach Therapiebeginn:

- im weiteren Verlauf:

4.1.3 Kreatinin-Clearence (in ml pro Minute)

- vor Therapiebeginn:

- nach Therapiebeginn:

- im weiteren Verlauf:

4.1.4 Harnstoff (in mg pro Deziliter)

- vor Therapiebeginn: 
- nach Therapiebeginn:

- im weiteren Verlauf:

4.1.5 Cholesterin (in mg pro Deziliter)

- vor Therapiebeginn:

- nach Therapiebeginn:

- im weiteren Verlauf:

4.1.6 Blutdruck

- vor Therapiebeginn:

- im weiteren Verlauf:

4.1.7 Sind Sie dialysepflichtig, wenn ja ab welchem Alter?

$\square$ ja $\rightarrow$ Alter: $\quad \square$ oder Verwandte an der Dialyse, mit welchem Alter?

$\square$ nein

4.1.8 Ist bei Ihnen eine Nierentransplantation durchgeführt worden?

$\square$ ja, $\quad$ wenn ja: Verwandtenspende (z.B. Mutter)

oder: unbekannte Spende $\square$

$\square$ nein

4.1.9 Wenn Sie transplantiert wurden, wann und mit welchem Ergebnis/ Verlauf?

- Datum

- Verlauf

\section{2 andere Organe}

\subsubsection{Hörverlust}

$\square$ ja $\quad \rightarrow$ Alter: $\quad \square$ wie stark (Hörverlust in $\mathrm{dB}$ ):

$\square$ nein

4.2.2 Lenticonus anterior

$\square$ ja $\rightarrow$ Alter:

$\square$ nein

$\square$ andere Augenbefunde

4.2.3 andere Symptome (Leiomyomatose, Makrothrombozytopenie, etc.)

\subsection{Nebenwirkung der Medikamente}

$\square$ Hyperkaliämie (hohes Blutkalium): 

$\square$ Husten:
$\square$ Hypotonie (niedriger Blutdruck):
$\square$ Akutes Nierenversagen:
$\square$ Rhabdomyolyse (Muskelzerfall):
$\square$ Sonstige Nebenwirkungen: 


\section{Literaturverzeichnis}

Abbate M, Benigni A, Bertani T, Remuzzi G (1999): Nephrotoxicity of increased glomerular protein traffic. Nephrol Dial Transplant $\underline{14}, 304-312$

Abbate M, Zoja C, Rottoli D, Corna D, Tomasoni S, Remuzzi G (2002): Proximal tubular cells promote fibrogenesis by TGF-beta1-mediated induction of peritubular myofibroblasts. Kidney Int $\underline{61}$, 2066-2077

Abrahamson DR, Prettyman AC, Robert B (2003): Laminin-1 reexpression in Alport mouse glomerular basement membranes. Kidney Int 60: 1037-1046

Alport AC (1927): Hereditary congenital haemorrhagic nephritis. Br Med J 1927, 1, 504-506

Atkin CL, Gregory MC, Border WA: Alport Syndrome. 4.Auflage; Little, Brown \& Company, Boston 1988

Bakris GL, Weir MR (2000): Angiotensin-Converting Enzyme Inhibitor-Associated Elevations in Serum Creatinine. Arch Intern Med 160, 685-693

Barker DF, Hostikka SL, Zhou J, Chow LT, Oliphant AR, Gerken SC, Gregory MC, Skolnick MH, Atkin CL (1990): Identification of mutations in the COL4A5 collagen gene in Alport syndrome. Science $\underline{248}, 1224-1227$

Brenner BM (1985): Nephron adaptation to renal injury or ablation. Am J Physiol 249, 324337 
Butkowski RJ, Wieslander J, Michael AF, Fish AJ (1990): Characterization of type IV collagen NC1 monomers and Goodpasture antigen in human renal basement membranes. J Lab Clin Med 115, 365-373

Chiurchiu C, Remuzzi G, Ruggenenti P (2005): Angiotensin-Converting Enzyme Inhibition and Renal Protection in Nondiabetic Patients: The Data of the Meta-Analyses. J Am Soc Nephrol 16, 58-63

Fischler MP, Follath F (1999): Comparative assessment of ACE inhibitors: what differences are relevant? Schweiz Med Wochenschr 129, 1053-1060

Flinter FA, Cameron JS, Chantler C, Houston I, Borrow M (1988): Genetics of classic Alport's syndrome. Lancet $\underline{1988}, \underline{2}, 1005-1007$

Gross O: Pathogenese und Prävention der Typ-IV-Kollagenerkrankung Alport Syndrom und Familiäre Benigne Hämaturie. Med. Habil.-Schr. Köln 2005

Gross O, Kashtan C (2009): Treatment of Alport Syndrome: Beyond Animal Models. Kidney Int $\underline{76}, 599-603$

Gross O, Weber M (2005a): From the molecular genetics of Alport Syndrome to principles of organo-protection in chronic renal diseases. Med Klin 100, 826-831

Gross O, Weber M (2005b): From Bench to bedside. Med Klin 100, 826-831 
Gross O, Koepcke ML, Beirowski B (2003a): Preemptive ramipril therapy delays failure and reduces renal fibrosis in COL4A3-knockout mice with Alport syndrome. Kidney Int $\underline{63}$, 438446

Gross O, Netzer KO, Lamprecht R (2003b): Novel COL4A4 splice defect and in-frame deletion in a large family as a genetic link between benign familial hematuria and autosomal Alport syndrome. Nephrol Dial Transplant $\underline{18}, 1122-1127$

Gross O, Koepcke ML, Weber M (2004): Alport-Syndrom und familiäre benigne Hämaturie. Nieren- und Hochdruckkrankheiten $\underline{7}, 348-356$

Gubler MC, Levy M, Broyer M, Naizot C, Gonzales G, Perrin D, Habib R (1981): Alport's Syndrome: A Report of 58 Cases and a Review of the Literature. Am J Med 70, 493-505

Hricik DE, Browning PJ, Kopelmann R, Goorno WE, Madias NF, Dzau VJ (1983): Captoprilinduced functional renal insufficiency in patients with bilateral renal-artery stenoses or renal artery stenosis in a solitary kidney. N Engl J Med $\underline{308}, 373-376$

Hudson BG, Tryggvason K, Sundaramoorthy M, Neilson EG (2003): Alports Syndrome, Goodspasture`s Alport`s Syndrome and Type IV Collagen. N Engl J Med Bio Chem $\underline{348}$, 2543-2556

Kashtan CE (1999): Alport Syndrome. An inherited disorder of renal, ocular, and cochlear basement membranes. Medicine $\underline{78}, 338-360$

Kashtan CE (2004): Familial hematuria due to type IV collagen mutations: Alport syndrome and thin basement membrane nephropathy. Curr Opin Pediatr $\underline{16}, 177-181$ 
Kashtan CE (2005): Familial hematurias: what we know and what we don`t. Pediatr Nephrol $\underline{20}, 1027-1035$

Kashtan CE (2007): Alport syndrome and the X-chromosome: implications of a diagnosis of Alport syndrome in females. Nephrol Dial Transplant 22, 1499-1505

Klahr S, Levey AS, Beck GJ (1994): The effect of dietary protein restriction and blood pressure control on the progression of chronic renal disease. N Engl J Med. 330, 877-884

Koepke ML, Weber M, Schulze-Lohoff E, Beirowski B, Segerer S, Gross O (2007): Nephroprotective effect of the HMG-CoA-reductase inhibitor cerivastatin in a mouse model of progressive renal fibrosis in Alport syndrome. Nephrol Dial Transplant 22, 1062-1069

Krishnamurti U, Chen Y, Michael A, Kim Y, Fan W, Wieslander J, Brunmark C, Rondeau E, Sraer JD, Delaure F, Tsilibary EC (1996): Integrin-mediated interactions between primary TSV 40 immmortalized human glomerular epithelial cells and type IV collagen. Lab Invest $\underline{74}$, $650-657$

Levy M, Feingold J (2000): Estimating prevalence in single-gene kidney diseases progessing to renal failure. Kidney Int $\underline{58}, 925-943$

Lewis EJ, Hunsicker LG, Bain RP, Rohde RD (1993): The effect of angiotensin-converting enzyme inhibition on diabetic nephropathy. N Engl J Med 329, 1456-62

Maschio G, Alberti D, Janin G (1996): Effect of the angiotensin-converting-enzyme inhibitor Benazepril on the progression of chronic renal insufficiency. N Engl J Med 334, 939-945 
Meehan DT, Delimont D, Cheung L, Zallocchi M, Sanson SC, Holzclaw JD, Rao V, Cosgrove D (2009): Biomechanical strain causes maladaptive gene regulation, contributing to Alport glomerular disease. Kidney Int $\underline{76}$, 968-976

Mezzano SA, Ruiz-Ortega M, Egido J (2001): Angiotensin II and renal fibrosis. Hypertension $\underline{38}, 635-638$

M’Rad R, Sanak M, Deschenes G, Zhou J, Bonaiti-Pellie C, Holvoet-Vermaut L, Heuertz S, Gubler MC, Broyer M, Grünfeld JP, Tryggvason K, Hors-Cayla MC (1992): Alport syndrome: a genetic study of 31 families. Hum Genet $\underline{90}$, 420-426

Mutschler E, Geisslinger G, Kroemer HK, Schäfer-Korting M: Mutschler Arzneimittelwirkungen. Lehrbuch der Pharmakologie und Toxikologie. 8.Auflage; Wissenschaftliche Verlagsgesellschaft mbH, Stuttgart 2001

Netzer KO, Gross O, Jung C, Kirsten R, Seibold S, Leinonen A, Weber M (1997): Alport Syndrome: Clinical and genetic correlation in a type- IV collagen disease. Hereditary Kidney Dis $\underline{122}, 116-123$

Nishimura M, Tanaka T, Yasuda T (1999): Effect of pravastatin on type IV collagen secretion and mesangial cell proliferation. Kidney Int Supp 56, 97-100

Proesmans W, Van Dyck M (2004): Enalapril in children with Alport syndrome. Pediatr Nephrol $\underline{19}, 271-275$ 
Rossing P, Hommel E, Schmidt UM, Parvin G (1993): Impact of arterial blood pressure and albuminuria on the progression of diabetic nephropathy in IDDM patients. Diabetes $\underline{42}, 715-$ 719

Ruggenenti P, Perna A, Gherardi G (1998): Renal function and requirement for dialysis in chronic nephropathy patients on long-term ramipril: REIN follow-up trial. Lancet $\underline{352}, 1252-$ 1256

Ruggenenti P, Perna A, Gherardi G (1999a): Renoprotective properties of ACE-inhibtion in non-diabetic nephropathies with non-nephrotic proteinuria. Lancet $\underline{354}$, 359-364

Ruggenenti P, Perna A, Benini R, Bertani T, Zoccali C, Maggiore Q, Salvadori M, Remuzzi G (1999b): In chronic nephropathies prolonged ACE inhibition can induce remission: Dynamics of time-dependent changes in GFR. Investigators of the Gisen Group. Gruppo Italiano Studi Epidemiologici in Nefrologica. J Am Soc Nephrol 10, 997- 1006

Ruß A: Arzneimittelpocket. 13.Auflage; Björn Brucksmeier Verlag, Grünwald 2008

Schaeffler A, Menche N: Mensch, Körper, Krankheit. 3.Auflage; Urban \& Fischer Verlag, München 1999

Sedman AB, Kershaw DB, Bunchman TE (1995): Recognition and management of angiotensin-converting enzyme inhibitor fetopathy. Pediatr Nephrol $\underline{9}, 382-385$

Slater EF, Merril DD, Guess HA, Roylance PJ, Cooper WD (1988): Clinical profile of angioedema associated with angiotensin-converting enzyme inhibiton. JAMA $\underline{260}, 967-970$ 
Tarver-Carr ME, Brancati FL, Eberhardt MS, Powe NR (2000): Proteinuria and the risk of chronic kidney disease (CKD) in the United States. J Am Soc Nephrol 11, 168

The Gisen Group (1997): Randomized placebo-controlled trial of effect of ramipril on decline in glomerular filtration rate and risk of terminal renal failure in proteinuric, non diabetic nephropathy. Lancet $\underline{349}, 1863-1875$

von Dicipinigaitis P (2006): Angiotensin-Converting-Enzyme-Inhibitor Induced Cough. Chest $\underline{129}, 169-173$

Welsch U, Dellert T: Lehrbuch Histologie. 3.Auflage; Urban \& Fischer, München 2005

Wenzel U, Wolf G (2003): Nephroprotektion durch Hemmung des Renin-AngiotensinSystems: Genügt ein Medikament? Mitt Klin Nephrol 32, 59-73

Wolf G (2005): Komplexität des RAAS. Med Klin 100: 471-477

Wühl E, Mehl SO, Schaffer F (2004): Antihypertensive and antiproteinuric efficacy of ramipril in children with chronic renal failure (ESCAPE-Study). Kidney Int $\underline{66}$, 768-776

Zatz R, Dunn BR, Meyer TW, Anderson S, Rennke HG, Brenner BM (1986): Prevention of diabetic glomerulopathy by pharmacological amelioration of glomerular capillary hypertension. J Clin Invest $\underline{77}$, $1925-19$ 


\section{Danksagung}

Hiermit möchte ich allen danken, die an der Erstellung der Dissertation beteiligt waren.

Mein ganz besonderer Dank geht an meinen Doktorvater PD Dr. med. Oliver Gross für die Überlassung des Themas, die rasche Hilfe bei Fragen und die konstruktive Kritik bei der Erstellung dieser Dissertation.

Für die statistische Betreuung bedanke ich mich besonders bei Dr. Katharina Lange, Dr. Klaus Jung und Simon Schneider aus der Abteilung der Medizinischen Statistik der Universität Göttingen.

Insbesondere möchte ich mich bei meinen Eltern Dörte und Wilfried Bach sowie meiner Schwester Verena für die konstruktive Kritik und Korrekturen bedanken. 


\section{Lebenslauf}

Ich, Christopher Michael Bach, bin am 17.September 1982 in Calgary, Kanada geboren. Nach einem dreijährigen Aufenthalt meiner Eltern (Vater: Dipl. Ing. Wilfried Bach; Mutter: Lehrerin Dörte Bach) in Kanada und nach meiner Rückkehr nach Deutschland im Jahre 1984 bin ich zusammen mit meiner älteren Schwester Verena in München aufgewachsen und habe im Juni 2002 mein Abitur am Gymnasium Pullach bei München abgelegt.

Anschließend habe ich eine Ausbildung zum Rettungssanitäter bei der Allgemeinen Sanitätshilfe München und Rettungsdienstschule Augsburg absolviert und abgeschlossen und zwei Jahre bei der Johanniter Unfallhilfe München gearbeitet.

Im Oktober 2004 habe ich mein Medizinstudium an der Georg-August-Universität in Göttingen begonnen und im März 2007 den ersten Abschnitt der Ärztlichen Prüfung abgelegt. Von Februar 2010 bis Januar 2011 absolvierte ich mein praktisches Jahr in den Kliniken für Anästhesiologie und Intensivmedizin im Pius Hospital Oldenburg, Allgemeinchirurgie am Kantonsspital Winterthur sowie Innere Medizin am National University Hospital Singapore und St.Bernward Krankenhaus Hildesheim. Im Mai 2011 legte ich den zweiten Abschnitt der Ärztlichen Prüfung ab.

Im Rahmen meines Studiums habe ich im September 2008 an der Abteilung Nephrologie und Rheumatologie des Zentrums Innere Medizin der Universität Göttingen unter der Leitung von Herrn Prof. Dr. med. Gerhard Anton Müller bei Herrn PD Dr. med. Oliver Gross mit meiner Arbeit an der Promotion begonnen. 